NBER WORKING PAPER SERIES

\title{
THE EFFECT OF POPULATION AGING ON ECONOMIC GROWTH, THE LABOR FORCE AND PRODUCTIVITY
}

\author{
Nicole Maestas \\ Kathleen J. Mullen \\ David Powell \\ Working Paper 22452 \\ http://www.nber.org/papers/w22452 \\ NATIONAL BUREAU OF ECONOMIC RESEARCH \\ 1050 Massachusetts Avenue \\ Cambridge, MA 02138 \\ July 2016, Revised June 2022
}

We are grateful to the Alfred P. Sloan Foundation Working Longer Program for grant funding. We thank Abby Alpert, Axel Börsch-Supan, David Cutler, Mary Daly, Edward Glaeser, Claudia Goldin, Larry Katz, Jim Poterba, Robert Willis, Dan Wilson, and the CBO Panel of Economic Advisers for valuable feedback, as well as participants of the 2014 SIEPR/Sloan Working Longer Conference at Stanford University, the Harvard Labor Economics Seminar, and CEPRA-NBER Conference on Ageing and Health (Lugano) for their many helpful comments. The views expressed herein are those of the authors and do not necessarily reflect the views of the National Bureau of Economic Research.

At least one co-author has disclosed additional relationships of potential relevance for this research. Further information is available online at http://www.nber.org/papers/w22452.ack

NBER working papers are circulated for discussion and comment purposes. They have not been peer-reviewed or been subject to the review by the NBER Board of Directors that accompanies official NBER publications.

(C) 2016 by Nicole Maestas, Kathleen J. Mullen, and David Powell. All rights reserved. Short sections of text, not to exceed two paragraphs, may be quoted without explicit permission provided that full credit, including $\odot$ notice, is given to the source. 
The Effect of Population Aging on Economic Growth, the Labor Force and Productivity

Nicole Maestas, Kathleen J. Mullen, and David Powell

NBER Working Paper No. 22452

July 2016, Revised June 2022

JEL No. J11,J14,J23,J26,O47

\section{$\underline{\text { ABSTRACT }}$}

Population aging is expected to slow U.S. economic growth. We use variation in the predetermined component of population aging across states to estimate the impact of population aging on growth in GDP per capita for 1980-2010. We find that each $10 \%$ increase in the fraction of the population ages $60+$ decreased per-capita GDP by $5.5 \%$. One-third of the reduction arose from slower employment growth; two-thirds was due to slower labor productivity growth. Labor compensation and wages also declined in response. Our estimate implies population aging reduced the growth rate in GDP per capita by 0.3 percentage points per year during 1980-2010.

Nicole Maestas

Department of Health Care Policy

Harvard Medical School

180 Longwood Avenue

Boston, MA 02115

and NBER

maestas@ hcp.med.harvard.edu

Kathleen J. Mullen

Center for Economic and Social Research

University of Southern California

635 Downey Way

Los Angeles, CA 90089

and NBER

kjmullen@usc.edu
David Powell

RAND Corporation

1776 Main Street

P.O. Box 2138

Santa Monica, CA 90407

dpowell@rand.org 
As the populations of developed countries become older than ever before, a persistent question has been what impact will this unprecedented demographic change have on economic growth and living standards? While demographic change is relatively easy to forecast because of its predetermined nature, it is more difficult to account for the ensuing economic adjustments that may dampen or amplify the effects of demographic change. This paper presents new empirical estimates of the realized effects of population aging on U.S. economic performance during 1980-2010 using state-level variation in predetermined demographic shifts as instrumental variables.

Our analysis begins with the observation that population aging has been playing out over recent decades with varying degrees of intensity throughout the country. For example, between 1980 and 1990, there was fast growth (above 15\%) in the older (ages 60 and older) population share in most Western states and in the Rust Belt, while at the same time 15 states, including California, Texas, New York, and Florida, experienced reductions in the older population share. Between 1990 and 2000, all but 12 states experienced a decline in the older population share as the large Baby Boom birth cohort passed through prime age. Then, between 2000 and 2010 population aging accelerated in most states -20 states experienced growth in the older population share of $15 \%$ or greater, including the northern Pacific and Mountain states, and nearly all the South Atlantic states.

Despite this wide variation across states and over time, simply comparing the economic outcomes of states that experienced fast versus slow population aging would likely generate biased estimates of the effects of population aging. This is because economic growth in a state can affect its age structure by influencing age-specific migration and mortality. For example, a negative trade shock disproportionately affecting one state could induce both a slowdown in economic growth and differential migration of younger workers to other states, making it appear as if population aging leads to slower economic growth when the reverse is true. This potential reverse causality makes it unlikely that the observed association between economic growth and population aging at the state level represents the causal impact of population aging.

Nevertheless, some of the observed variation in population aging across states was in fact determined many years prior; this historical age structure shaped the relative sizes of age cohorts far into the future. Under certain conditions, this predetermined component can be used as an instrumental variable for the realized aging experienced by a state many years later, thus 
enabling estimation of the causal effect of population aging on economic growth and its components. The key identifying assumption is that a state's past age structure affects its future changes in economic outcomes only by affecting its subsequently realized age structure. To satisfy the exclusion restriction, the past age structure instrument must be sufficiently predetermined so that it is not itself a function of long-run trends predictive of future economic growth. To address this requirement, we take the "initial" age structure in each statealternatively measured 10,20,30, and 40 years prior to the outcome year-and apply national cohort survival ratios to predict the older population share in each state in the baseline outcome year. Moreover, we study decadal changes in aging and economic growth to account for the independent effects of prior age structure. As the lags used to predict future population aging grow more distant, it becomes less and less likely that the initial age structure could have been influenced by the same trends driving contemporaneous economic growth in a state.

We estimate the effect of state population aging - measured as the 10-year growth rate in the older population share — on decadal growth in state GDP per capita, using each of the lagged instruments separately. As the lags grow more distant, the strength of the instrument attenuates, but even so, our estimates are stable across the different lagged versions of our instrumental variable, indicating little influence of unobserved trends on the instrumental variables estimates. The estimates are also robust to many alternative specifications, including a dynamic model with lags of the dependent variable and conditioning on changes in other age group shares (and separately identifying them using the historical age structure).

Our preferred elasticity estimates imply that $10 \%$ growth in the fraction of the population ages 60 and older - equivalent to a 2.4 percentage point (pp) increase in the share $60+-$ decreases GDP per capita by 5.5\%. Given our focus on decadal growth, we interpret our estimates as evidence of the effect of population aging on medium-run economic growth. To understand the channels through which population aging reduces economic growth, we decompose GDP per capita into GDP per hours worked (which we refer to as "labor productivity"), employment per capita ("employment rate"), and the number of hours per worker ("intensive labor supply"). We regress each component of log growth in GDP per capita on (instrumented) growth in the log older population share to obtain a set of coefficients that sum to the coefficient on the older share from the regression for GDP per capita $(-5.5 \%)$. The coefficients from this channel decomposition exercise imply that a $10 \%$ increase in the older 
population share results in a $3.4 \%$ decrease in output per hour worked, a $1.7 \%$ decrease in workers per capita, and a minimal effect on intensive labor supply. Thus, two-thirds of the aginginduced reduction in GDP per capita growth arose from a reduction in labor productivity growth, while one-third was due to a reduction in growth in employment per capita.

The $3.4 \%$ reduction in labor productivity is matched by a reduction in labor compensation per hour worked of equivalent magnitude $(-3.3 \%)$. We find reductions in wage growth across the age distribution, suggesting the decline in labor productivity was broad based. To shed light on the mechanisms behind the aging-induced decline in labor productivity, we use researcher-compiled data on the physical capital stock by state (available for the period 19802000) and find a statistically insignificant but positive effect of population aging on growth in physical capital. We interpret this as suggestive evidence of a small offsetting effect of capital deepening.

A limitation of our research design is that generalizability from states to nation requires a degree of caution, since state-based research designs deliberately avoid capturing any federal policy responses that accrue uniformly across states. Ramey (2011) points out that in some settings, state responses can be offset in aggregate by federal policy. We discuss this issue in the context of our setting in Section VI. At the same time, state-based research designs offer clear advantages over cross-national designs, which are vulnerable to bias from unobserved heterogeneity in national pension systems, labor market policies and cultural norms. Indeed, an advantage of using variation across economic units within the same country is that these effects are held constant (e.g., Barro and Sala-i-Martin, 1992). Importantly, our estimates incorporate all downstream effects of population aging that vary across states, such as aging-induced reductions in the business startup rate, aging-induced technology adoption, aging-induced changes in capital intensity, and aging-induced migration or shifts in industry composition across states. At the same time, our research design does not attribute to population aging confounders such as changes in migration, industry composition or business dynamism that arise from other factors, such as trade shocks, skill-biased technical change (Salgado 2020, Kozeniauskas 2017), or changes in tax incentives that may have encouraged firm mobility and differential migration of older versus younger workers.

Our paper contributes essential evidence to the literature on the macroeconomic effects of changes in population age structures. This literature primarily uses cross-country research 
designs and optimization models and has often directed attention to the effects of workforce aging on growth in output per worker, as opposed to the more encompassing effects of population aging. ${ }^{1}$ Findings from this literature have been mixed. Most studies conclude the relationship between aging and output is negative (e.g., Sheiner et al. 2007; Sheiner 2014; Gagnon et al. 2021), but another strand of literature argues the relationship could be positive due to labor scarcity triggering capital deepening and/or investments in automation sufficient to offset the downward pressures (e.g., Cutler et al. 1990; Acemoglu and Restrepo 2017). Others have countered that the scope for capital deepening is limited in countries like the U.S., especially as interest rates have reached historical lows (Börsch-Supan 2003; Eggertsson et al. 2019).

Our paper also contributes to a closely related literature that utilizes production functions and decompositions to interpret past growth in GDP per capita for the purpose of forecasting future growth (e.g., Gordon 2016; Fernald, 2016; Fernald and Jones 2014). This literature recognizes population aging as an important contributor to the slowdown in U.S. economic growth and offers forecasts of future growth that account for its negative effects; however, these analyses tend to focus on the labor force growth channel, ignoring potential effects of aging on labor productivity. In sharp contrast, our analysis finds population aging has had a large, detrimental effect on U.S. labor productivity in recent decades in addition to and larger than its expected slowing of employment growth. Only a handful of studies have explicitly considered effects on labor productivity, and their focus has been exclusively on workforce aging (Feyrer 2007, 2008; Aiyar et al. 2016; Daniele 2020).

Our estimates indicate that population aging has had a significant impact on the annual rate of economic growth in the U.S. For example, the older share increased by $16.8 \%$ in the U.S. between 1980 and 2010. Our elasticity estimate then implies that per capita GDP over that period was $9.2 \%$ lower than it would have been absent the effects of population aging. In terms of

\footnotetext{
${ }^{1}$ Other studies in the growth literature have considered the importance of the "dependency ratio" without focusing on population aging specifically. Bloom, Canning, and Sevilla (2003) examine the implications of a changing age structure for economic growth in developing countries. Kögel (2005) measures the effect of changes in the youth dependency ratio on total factor productivity. More recently, Aksoy et al. (2015) model the effects of demographic changes on long run economic growth accounting for endogenous fertility, education and innovation.
} 
annual growth, population aging reduced growth by 0.3 pp per year during our study period, ${ }^{2}$ when the average rate of growth was 1.88 pp per year. Similar calculations suggest that population aging reduced growth by 1.2 pp per year for 2010-2020 and will account for an average loss of 0.6 pp per year between 2020-2030.

In the next section, we describe our data and summarize the variation in population aging and economic growth across states between 1980 and 2010. In Section II, we present our instrumental variables research design. Section III shows our estimates of the effect of population aging on economic growth, along with a series of robustness tests. In Section IV, we use channel decomposition techniques to estimate which production channels are relatively more affected by population aging. We investigate spillover effects on younger workers in Section V. Section VI addresses generalizability to the national level and tests for evidence of skill reallocation. We conclude in Section VII with further discussion of our estimates in the context of the literature and report the implied magnitudes of our estimates for recent and future annual economic growth.

\section{Population Aging and Economic Growth: Data and Summary Statistics}

The U.S. population has aged nearly continuously over the last century. Figure 1 shows the percent of the population aged 60 and older starting in 1900 and projected through 2050 . The only decade in which the population did not age was the 1990s when the Baby Boom passed through the middle of the age distribution. The U.S. population is projected to continue aging, at a relatively faster rate through 2030 (due again to the Baby Boom), and at a slower rate thereafter. U.S. population aging today results from the sharp decline in the birth rate in the 1960s, which marked the end of the Baby Boom, and the long-running decline in mortality rates among some population groups. Immigration can offset these demographic forces to some degree but has not been of sufficient magnitude to reverse population aging.

To investigate population aging at the state level, we use state population counts by age from the 1950, 1960, 1970, 1980, 1990, and 2000 Census Integrated Public Use Microdata Series (IPUMS) and the 2009-2011 American Community Surveys (ACS) (Ruggles et al., 2015). Due

\footnotetext{
${ }^{2}$ Our estimates imply that a $16.8 \%$ increase in the older share would decrease per capita GDP by $9.2 \%$. Define $\tilde{g}$ as the population aging "penalty" in annual growth rate that results in a $9.2 \%$ decrease in per capita GDP 30 years later; let $g$ represent the annual growth rate in the absence of aging. Then, $(1-0.092)(1+g)^{30}=(1+g-\tilde{g})^{30}$, where $g-\tilde{g}$ is observed and equal to 0.0188 for the U.S. for $1980-2010$. Thus, $\tilde{g}=0.003$.
} 
to the relatively small size of the ACS, we combine the 2009-2011 samples to construct a "2010 Census." 3 In addition to population counts, the Census and ACS contain individual-level data measuring employment status, hours worked and labor earnings in the preceding calendar year. ${ }^{4}$ We aggregate these data to the state-year level to obtain state employment levels, total hours worked $^{5}$ and total labor earnings. We also construct labor market measures at the level of twodigit industry, state and year. ${ }^{6}$

To measure aggregate economic output, we acquire GDP by state ${ }^{7}$ and year from the Bureau of Economic Analysis (BEA). ${ }^{8}$ State GDP is defined as "the value added in production by the labor and capital located in a state." These data "provide a comprehensive measure of a state's production." 9 Because the annual labor outcomes from the Census and ACS refer to the previous year (i.e., 1979 in the 1980 Census), we match GDP data from the year preceding the indicated Census year (i.e., 1979, 1989, 1999 or 2009). ${ }^{10}$ However, for ease of exposition, we refer to the Census years when indexing by time below.

\footnotetext{
${ }^{3}$ Alternatively, we could have used state-level population statistics from the Census. However, we chose to construct our population size and labor supply measures from the same individual-level data in order to minimize differences arising from differences in data aggregation procedures. Using these noisier measures of state-level population should not affect the consistency of our estimates but may increase our standard errors.

${ }^{4}$ There is evidence that the income data between the Census and ACS are not comparable due to survey changes. https://www.census.gov/content/dam/Census/library/working-papers/2003/acs/2003 Nelson_01.pdf (last accessed August 18, 2018) finds that ACS household income is $4.6 \%$ lower than Census household income. We assume that time fixed effects account for this change or, more precisely, that this change is not correlated with our instrument after conditioning on time fixed effects. We also show results by decade. The 1980-1990 and 1990-2000 samples rely on Census data only and avoid this issue.

${ }^{5}$ We calculate annual hours for each person as the usual hours worked per week times the number of weeks worked. Weeks worked is only reported in intervals in the ACS. Using Census data, we regress number of weeks on categorical indicators for each of these intervals and impute the number of weeks.

${ }^{6}$ We use the 1990 Census Bureau industrial classification scheme, which is consistently reported in IPUMS for all years since 1950.

${ }^{7}$ While GDP at the state level is likely subject to more measurement error concerns than national GDP figures, we assume that this measurement error is not correlated over time with our predicted population aging measures.

${ }^{8}$ Last accessed March 31, 2015. The BEA cautions that there is a discontinuity in the state GDP time series due to a switch from SIC industry codes to NAICS industry codes. We assume that time fixed effects account for this shift and that any differential changes across states are not correlated with our instrument (predicted changes in aging). The literature has appended pre-1997 state GDP data to post-1997 state GDP data before (e.g., Nakamura and Steinsson, 2014). Also note that we present results by decade, which show that our results are not driven by changes between 1990 and 2000.

${ }^{9}$ An advantage of using aggregate production instead of consumption data is that GDP includes asset income, which can be used to compensate for declines in consumption.

${ }^{10}$ There is still a slight misalignment between state and year for the labor outcomes since, before 2000 , the Census only included information on state of residence in the current year. For 2000 and 2010 it is possible to aggregate labor outcomes by state of residence in the previous year. We conduct robustness checks of our main regressions for 2000-2010 using the aligned and misaligned measures, respectively, and found that this did not affect our results. These estimates are shown in Appendix Table A.10 and discussed below.
} 
The BEA also collects state-level data on total employee compensation, which includes wages and salaries paid to employees as well as noncash benefits. Wages and salaries are the primary component of employee compensation and include overtime pay, sick and vacation pay, severance pay, incentive payments (e.g., commissions, tips, and bonuses), and voluntary contributions to deferred compensation plans. Noncash benefits include in-kind benefits and employer contributions to pension plans, health insurance, and social insurance programs. We use the BEA employee compensation data as a measure of full labor compensation in a state, and as a complement to the Census earnings data. ${ }^{11}$

We construct growth rates by state for all of our analysis variables. These data are presented in Table A.1, where growth in a variable as of Census year $t$ refers to the percent change between $t-10$ and $t$. The top panel shows all Census years pooled, while the lower panels show the data decade by decade. There is significant variation across states in the size and growth rate of the $60+$ population in all years. In the pooled sample, the fraction (of the ages $20+$ population) ages $60+$ ranges across states and Census years from 0.095 to 0.313 , with mean 0.240 and standard deviation 0.029 . The 10 -year growth rate of the fraction $60+$ ranges from $-9 \%$ to $47 \%$, with mean $4 \%$ and standard deviation $8 \%$. Economic growth also varies substantially across states and years. In the pooled state-year sample, the 10-year real growth rate in GDP per capita ranges from $-35 \%$ to $46 \%$, with mean $9 \%$ and standard deviation $9 \% .{ }^{12}$ Growth in employment per capita ranges from $-10 \%$ to $9 \%$, with mean $-0.3 \%$ and standard deviation $4 \%$.

The regional patterns underlying the variation in population aging in Table A.1 are shown decade by decade in Appendix Figures 1A, 1B, and 1C. ${ }^{13}$ Between 1980 and 1990 (Appendix Figure 1A), there was relatively fast growth in the older population in the West and in the Rust Belt. At the same time, 15 states, including the large states of California, Texas, Florida, and New York, experienced a contraction in the relative size of their older population. Between 1990 and 2000 (Appendix Figure 1B) the majority of states experienced declines in the relative

\footnotetext{
${ }^{11}$ One limitation of the BEA measure of total compensation is that it does not include compensation for the selfemployed. Adding in labor earnings for the self-employed using the Census and ACS has little effect on the results. ${ }^{12}$ This growth rate is not directly comparable to national per capita GDP growth over this time period. First, we are scaling GDP by the size of the population ages $20+$, not the full population size. Second, we are reporting the average growth rate across states weighted by initial $20+$ population size. To construct the national growth rate, one would want to weight by GDP size in the initial period.

${ }^{13}$ Hawaii and Alaska are not shown in Appendix Figures 1A-1C but are included in our analysis sample.
} 
size of their older populations, with just 12 small states seeing weakly positive growth. However, between 2000 and 2010 (Appendix Figure 1C) the growth rate of the older population share was above 15\% in 20 states, including the northern Pacific and Mountain states, and nearly all of the South Atlantic states. Only 4 states - Florida, North Dakota, South Dakota, and the District of Columbia - experienced less than 5\% growth during this period. Florida is notable in that by this time it already had a relatively high older population share. Appendix Figures $2 \mathrm{~A}-2 \mathrm{C}$ show the equivalent variation in economic growth rates by state and decade.

\section{Research Design}

Our causal model of interest relates the older population share in a state-to-state output per capita. To normalize comparisons of growth across states with different older population shares, we take first differences of log levels to arrive at our specification for growth in GDP per capita between Census years $t$ and $t+10$ :

$$
\ln \left(\frac{G D P_{s, t+10}}{N_{s, t+10}}\right)-\ln \left(\frac{G D P_{s t}}{N_{s t}}\right)=\beta\left[\ln \left(\frac{A_{s, t+10}}{N_{s, t+10}}\right)-\ln \left(\frac{A_{s t}}{N_{s t}}\right)\right]+X_{s t}^{\prime} \delta_{t}+\gamma_{t}+\left(\varepsilon_{s, t+10}-\varepsilon_{s t}\right),
$$

where the outcome is the change in the log of GDP per person aged 20 and older in state $s$ between Census year $t$ and Census year $t+10$ (or a related outcome), $A_{s t}$ is the number of individuals aged 60 and older in state $s$ and year $t,{ }^{14} N_{s t}$ represents the state population aged 20 and older in year $t,{ }^{15}$ and $X_{s t}$ contains a set of time-varying control variables whose influence is also allowed to vary over time. The $\gamma_{t}$ term represents time fixed effects and $\varepsilon_{s t}$ represents state output shocks. The coefficient $\beta$ measures the effect of the older population share on GDP per capita. By estimating in first differences, we account for fixed differences across states.

Under this specification, $\beta$ is interpretable as an elasticity. We include in $X$ the initial (period $t$ ) two-digit industry composition of state employment (specifically, the log of the fraction of workers in each industry ${ }^{16}$ ) to further account for initial conditions that may predispose states to particular growth paths. ${ }^{17}$ We will also show that our results are not

\footnotetext{
${ }^{14}$ We choose $60+$ as our definition of the aged population, rather than $65+$, because approximately one-third of Americans claim Social Security retirement benefits at age 62, the earliest claiming age. Early claiming tends to coincide with labor force exit.

${ }^{15}$ Both the outcome and main explanatory variable are normalized by the size of the $20+$ population in the stateyear, which makes interpretation straightforward. Throughout the paper, we refer to variables normalized by the size of the $20+$ population as "per capita" variables.

${ }^{16}$ Results are similar throughout the paper if we use levels.

${ }^{17}$ In complementary work, we find that an area's initial industry structure predicts changes in labor outcomes (see Maestas, Mullen and Powell, 2013).
} 
sensitive to the log-log functional form shown in equation (1). Specifically, we estimate similar implied elasticities if we use $\left[\left(\frac{A_{s, t+1}}{N_{S, t+10}}\right)-\left(\frac{A_{s t}}{N_{s t}}\right)\right]$ instead of $\left[\ln \left(\frac{A_{s, t+10}}{N_{S, t+10}}\right)-\ln \left(\frac{A_{s t}}{N_{s t}}\right)\right]$.

While equation (1) relates state population aging to changes in state economic outcomes, changes in the age structure of a state may depend - in part - on factors related to economic growth. For example, economic decline could induce prime-aged workers to migrate out of the state while older workers may be more likely to stay given the smaller lifetime return to moving. Consequently, we would observe that aging states have less favorable economic outcomes, though this relationship is not causal. ${ }^{18}$ Similarly, differential industry growth and decline across states may affect mortality rates and these mortality effects may not be uniform across all age groups, directly altering the age composition of states depending on their economic conditions.

To address these potential confounders, we estimate equation (1) using an instrumental variables strategy that exploits variation in the predetermined component of population aging across states over time. The key identifying assumption is that a state's past age structure affects future changes in economic outcomes only by affecting its subsequently realized age structure, and not through any other channel. ${ }^{19}$ To satisfy this requirement, we take each state's "initial" age structure - alternatively measured $0,10,20$, and 30 years prior to the baseline Census year $t$ - and apply common cohort survival ratios (as experienced nationally, not by state) to predict the older share of population in each state 10,20,30 and 40 years into the future. As the lags grow more distant, it becomes less and less likely that the initial age structure could have been influenced by the same trends driving contemporaneous economic growth in a state.

More precisely, we use the age structure in year $t-x$ to predict changes in the log of the fraction of the state population aged 60+ between periods $t$ and $t+10$, where $x \in$ $\{0,10,20,30\}$ corresponds to lag lengths of $\{10,20,30,40\}$ from $t+10$. For example, $x=10$

\footnotetext{
${ }^{18}$ There is some evidence that population aging itself may affect interstate migration; see Karahan and Rhee (2014).

${ }^{19}$ Alternatively, one can imagine using historical birth rates to predict current age structures. We do not take this approach for two reasons. First, given the timing of our data, we would need birth rates back to the early 1900's. These data are not available for many states. Second, there are advantages to generating predicted age structures using the age distribution at a fixed point in time. This approach permits us to test the sensitivity of the results as we go further back in time to generate the instruments. Using birth rates would require using a long time series of years to generate variation, and the equivalent sensitivity exercise would be more difficult. We do not find that our results are driven by the timing of the age structure that we use so there is likely little gain in altering this approach.
} 
implies that the period $t-10$ age structure is used to predict both the period $t$ and period $t+10$ age structures. $^{20}$ We refer to this as a 20-year lag length. Our instruments are generated using:

$$
\begin{aligned}
& \ln \left(\frac{\widehat{A}_{s, t+10}}{\widehat{N}_{s, t+10}}\right)-\ln \left(\frac{\widehat{A}_{s, t}}{\widehat{N}_{S, t}}\right), \\
& \text { where } \quad \hat{A}_{s, t+10}=\sum_{j \geq 60-x-10} \underbrace{N_{j s, t-x}}_{\begin{array}{c}
\text { Total number } \\
\text { of people age }
\end{array}} \times \\
& j \text { in state } s \\
& \text { at time } t-x \\
& \hat{A}_{s, t}=\sum_{j \geq 60-} \underbrace{N_{j s, t-x}}_{\begin{array}{c}
\text { Total number } \\
\text { of people age } \\
j \text { in state } s
\end{array}} \times \underbrace{\frac{N_{j+x, t}}{N_{j, t-x}}}_{\begin{array}{c}
\text { National survival } \\
\text { rate }
\end{array}} \\
& \text { at time } t-x \quad \text { of cohort age } j \text { between } t-x \text { and } t \\
& \text { and } \widehat{N}_{s, t+10}=\sum_{j \geq 20-x-10} N_{j s, t-x} \times \frac{N_{j+x+10, t+10}}{N_{j, t-x}}, \quad \widehat{N}_{s, t}=\sum_{j \geq 20-x} N_{j s, t-x} \times \frac{N_{j+x, t}}{N_{j, t-x}} \text {. }
\end{aligned}
$$

To predict the state age structure in year $t$, we use national census survival rates, defined as the ratio of the national population age $j+x$ in one Census to the cohort's population size in a previous Census (at age $j$ ). ${ }^{21}$ We then multiply the number of individuals age $j$ in the state in one Census by the age-specific national survival rate to predict the number of individuals age $j+x$ in the state in a subsequent Census. For example, to predict the number of 60 -year-olds in Alabama in 2000, we multiply the number of 40-year-olds in Alabama in 1980 by the national ratio of 60-year-olds in 2000- to 40-year-olds in 1980. This approach uses the initial state age composition interacted with national level cohort changes and has the advantage of disregarding variation resulting from differential state-level migration and mortality for identification. ${ }^{22}$ The instrument is similar in spirit to the Bartik instrument (Bartik, 1991; Blanchard and Katz, 1992), which predicts local economic growth by interacting national industry-specific growth with initial local industry composition. Given recent discussions of shift-share instruments (e.g.,

\footnotetext{
${ }^{20}$ When $x=0$, the predicted period $t$ age structure is the actual period $t$ age structure. The instrument is the predicted change in aging given this original age structure.

${ }^{21}$ Our census survival ratios incorporate international (as opposed to interstate) migration.

${ }^{22}$ Other approaches, such as using survival tables, for predicting national-level changes in cohort sizes are also possible. Since these national-level changes are simply being used to weight differences in earlier state-level age structures, there is likely little gain (or loss) in slight alterations of the proposed approach.
} 
Goldsmith-Pinkham et al., 2020), we note that the main source of variation used by the instrument is the variation across states in the relative sizes of 10 -year birth cohorts in year $t-x .^{23}$

For example, the 10-year lag primarily uses variation across states 10 years prior to $t+10$ in the size of their populations aged 50-59, while the 20-year lag uses variation across states 20 years prior in the number of 40-49-year-olds, and the 30-year lag uses variation from 30 years prior in the number of 30-39-year-olds. States that had relatively more individuals of a given age cohort in the past are predicted to experience relatively large increases in the number of older individuals in the future. ${ }^{24}$ The assumption of this variation is that prior age structure does not predict changes in economic growth between periods $t$ and $t+10$, except through its relationship with changes in population aging during that time period. We specify our main estimating equation in differences to account for the independent effects of prior age structure (and other cross-state differences) on current economic outcomes. In the next section, we provide several tests concerning whether our instrument is correlated with underlying economic trends. We find little evidence of confounding trends. ${ }^{25}$

The variation in the population age structure that we exploit is predictable and observable by residents of the state before time $t$. In this manner, the instrument parallels population aging at the national level. The literature has used lags of the age structure to predict the current age structure as a way to avoid confounding by endogenous migration (e.g., Shimer, 2001; Jaimovich and Siu, 2009; Aiyar et al., 2016).

\footnotetext{
${ }^{23}$ While Goldsmith-Pinkham et al. (2020) recommend using the baselines shares (in this case, baseline age shares) as instruments in themselves, this approach is disputed. See Borusyak et al. (2021) and Tim Bartik's comment found here: http://blogs.worldbank.org/impactevaluations/rethinking-identification-under-bartik-shift-shareinstrument (last accessed August 20, 2018). To summarize this emerging literature, there are benefits to providing weights to appropriately aggregate the initial shares into a single instrument, as we have done.

${ }^{24}$ Some variation may also come from changes in the denominator $N$. That is, if the younger population is (predictably) growing faster in one state than in another, the first state will have less population aging by our metric even if the two states experienced the same (absolute or proportional) change in the number of older individuals.

${ }^{25}$ For the instruments based on 30-year and 40-year lags, we cannot predict the size of youngest age groups 30 and 40 years later since the youngest cohorts had not yet been born. We set the size of these cohorts to zero such that identification is originating from differential baselines for observed cohorts that predict the size of the $60+$ age group, relative to observed cohorts that predict the size of the under-60 age group. Since no identification is originating from the assignment of these zeroes, this method should not create any problems, unless birth rates change systematically in our sample such that they unravel the first stage (i.e., substantially higher birth rates in areas that otherwise would have experienced growth in the elderly share). The existence of a strong first stage relationship would suggest this is not the case. Alternative imputation methods to improve the strength of these instruments are possible, such as predicting birth cohort sizes based on baseline demographics. However, the validity of the instruments would depend on the appropriateness of the underlying assumptions since some variation would originate from the imputation. Our decision is conservative and avoids identifying off of such assumptions.
} 
We estimate equation (1) using 2SLS. We weight our regressions by period $t$ population, though we provide unweighted estimates as well. We adjust standard errors for clustering at the state-level.

\section{Effect of Population Aging on Economic Growth}

\section{A. Main Estimates}

We begin with a visual depiction of our research design in Figure 2. Each data point is an observation of the decadal change in a state, weighted by population size in the base year. Figure 2A shows the strong negative association in the raw data between realized population aging and per capita GDP growth over the period 1980-2010. Figure 2B shows the first-stage relationship between realized aging and predicted aging (using the 10-year lagged instrument). Here, we see that realized population aging is strongly predicted by the instrument. Finally, Figure $2 \mathrm{C}$ presents the visual reduced form relationship between the predicted aging instrument and subsequent economic growth, which is negative and statistically significant.

Table A.2 presents the ordinary least squares (OLS) coefficients summarizing the relationship between aging and economic growth once we include controls for state industry composition in the initial period interacted with time fixed effects (to account for long-lasting shocks that may vary with initial industry composition). The table shows OLS estimates of $\beta$ (equation 1) for the entire time period 1980-2010, and separately for each decade. The dependent variable is the decadal change in log per-capita GDP in a state. The point estimates indicate that states experiencing growth in the fraction of individuals ages $60+$ also experience slower growth in per capita GDP. Pooling all three decades, we estimate that a $10 \%$ increase in the fraction of the state population ages $60+$ is associated with a decrease in per capita GDP of $8.3 \%$. Limiting the sample to one ten-year difference at a time, we consistently find a large and statistically significant conditional association between population aging and per capita GDP growth.

As noted above, there are many reasons why state populations might age at different rates and economic growth itself could impact the state age structure by affecting migration decisions; this would bias the OLS estimate away from zero if younger workers move to faster growing places to pursue new job opportunities or, conversely, if older individuals move to slower growing places to take advantage of the lower cost of living. Similarly, if economic growth 
affects mortality rates, then this too may contribute bias, though the direction of the bias is less obvious in this case since it depends on how any growth-induced mortality changes play out across the age distribution.

Panel A of Table 1 presents the reduced form relationship between our instruments - the predicted change in the log of the fraction of individuals $60+$ in a state-and economic growth. When we predict the older share using the age structure 10 years prior, we find that a $10 \%$ increase in the predicted older share results in a 3.9\% decrease in per-capita GDP. Using the age structure 20 and 30 years prior to predict the older share results in nearly identical reduced form estimates of $3.1 \%$. The reduced form using the age structure 40 years prior is somewhat smaller at $2.5 \%$.

Table 1, Panel B shows the first-stage coefficients for the different instruments. When we predict the older share using the age structure 10 years prior, we find that a $10 \%$ increase in the predicted older share results in a $7.2 \%$ increase in the actual older share. As one would expect, the first stage generally decreases as we use longer lags of the age structure to predict future demographic changes: a 10\% increase in the older share predicted from the age structure 20 years prior results in a realized $6.2 \%$ increase in the older share; the realized increase is $6.9 \%$ when we use the age structure 30 years prior and $4.6 \%$ when we use the age structure 40 years prior to predict the older share. Accordingly, the first-stage F-statistic is 174.2 when we use a 10year lag, 103.5 for the 20-year lag, 85.1 with the 30-year lag, and 13.0 using a 40-year lag.

The IV estimates of $\beta$ are shown in Panel C Table 1. Across the board, the IV estimates are smaller in magnitude than the OLS estimate, consistent with bias in the OLS estimate from economically induced migration of younger individuals to faster growing areas. ${ }^{26}$ Instrumenting with the 10-year lagged age structure, we estimate that a $10 \%$ increase in the fraction of the population $60+$ (equivalent to a 2.4 pp increase in the share $60+$ ) decreases per-capita GDP by $5.5 \%$. The estimates are similar when we instrument with longer lags of the age structure-we obtain an estimated decrease of 5.0\% using the 20 -year lagged age structure, a $4.5 \%$ decrease with the 30-year lagged age structure, and a (statistically insignificant) 5.4\% decrease with the 40-year lagged age structure. The consistency of the estimates across the instruments suggests

\footnotetext{
${ }^{26}$ The difference between the 1980-2010 OLS and IV estimates using the 10-year lagged instrument is marginally statistically significant $(\mathrm{p}=0.06)$. We test the equality of the estimates through a clustered bootstrap method and report how frequently the OLS estimate is smaller than the IV estimate.
} 
that the IV estimate based on the 10-year lagged age structure is not confounded by underlying economic trends (i.e., that estimating in first differences is appropriately accounting for the independent effects of the initial period- $t$ age structure). We therefore use this more precisely estimated coefficient as our main estimate for the robustness tests and decompositions in the following sections. Appendix Table A.3 shows the reduced form, first stage, and IV estimates separately by decade. We estimate that aging reduces per-capita GDP in each decade.

\section{B. Robustness of the Main Estimates}

In this section, we examine the robustness of the main estimates to factors such as changes in the shares of younger age groups, confounding trends in output or mean reversion, alternative functional forms, weighting, common regional shocks, and mismeasurement of state of residence.

\section{B.1. Robustness to Changes in the Share of Younger Age Groups}

While our specification models changes in per capita GDP as a function of changes in the older population share, economic growth may also be affected by changes at other points of the age distribution. Moreover, predicted increases in the $60+$ population share may be correlated with predictable growth in the share of other age groups, suggesting the possibility of an omitted variable related to changes in other age group shares. We can test for this possibility explicitly given that our instrumental variables strategy is easily extended to predict growth in other age groups. To implement this, we include multiple age groups in our specification and, as before, estimate our main model using two-stage least squares, where the instruments are the predicted changes in each included age group using the same prediction method as before (based on 10year lags of the state age structure). The results are presented in the top half of Appendix Table A.4. We find that only growth in the $60+$ population leads to a statistically significant decrease in GDP per capita. When we include all other age groups, the estimate is nearly the same as before-a $10 \%$ increase in the fraction of the population aged $60+$ is associated with a $5.9 \%$ decrease in per-capita GDP. Including or excluding the other age groups has little effect on this estimate. Consequently, we conclude that separately identifying these other age groups is unnecessary for consistent estimation in our context. We provide further support for this conclusion and return to this table when discussing the role of functional form restrictions below. 


\section{B.2. Robustness to Confounding Trends in Output or Mean Reversion}

Growth in a state's older share may be a function of the state's economic conditions, potentially confounding the causal relationship between aging and growth. OLS estimates of equation (1), as shown above in Table A.2, reveal a strong negative correlation between aging and growth, even when accounting for state fixed effects (through differencing) and time fixed effects. Our instrumental variable strategy is designed to disentangle the reverse effect of growth on realized population aging from the effect of population aging on growth by using predicted changes in the state's population structure. Our IV estimates suggest that the OLS estimates are, in fact, biased away from zero, as one would expect if the older share were systematically affected by economically induced migration patterns.

The instrumental variables strategy assumes that the initial age distribution of a state is not predictive of trends or mean reversion in economic output except through changes in the state age structure (Goldsmith-Pinkham et al., 2020). Our primary evidence that the identifying assumption is valid is the robustness of our estimates to use of longer lags of the age structure (Table 1). Further evidence supporting this assumption is that, if the initial age structure predicts differential economic growth, then we might expect to see statistical relationships across other age groups as well. However, as discussed above, Table A.4 shows that only changes in the share aged $60+$ are statistically related to changes in per capita GDP. It is unlikely that the instrument for the change in the share $60+$ (here, variation is primarily driven by differences in the share ages 50-59 10 years prior) would uniquely predict confounding trends, while variation in every other initial age group share would have no relationship to those same trends (e.g., the instrument for the change in the share 40-49 is primarily based on the share 30-39 10 years prior).

Next, in Appendix Table A.5, we report estimates from a specification that controls for the prior value of the outcome to account for trends dependent on initial economic conditions. This control is potentially important given previous evidence of convergence across states (Barro and Sala-i-Martin, 1992). Because of the biases associated with estimating a specification with a lagged dependent variable, we use a GMM estimator using lagged values as instruments. In Column (1), we present estimates using (all available) lagged values of the log of per capita GDP as instruments. The estimate is larger in magnitude than our main estimate. In Column (2), we replicate this specification but do not use the $t-10$ value of the log of per capita GDP as an 
instrument, relying only on lags further back in time. The exclusion of this instrument reduces the possibility that the lagged instruments are themselves endogenous due to serial correlation in the error term. The Column (2) estimate is even larger in magnitude. Overall, these results indicate that underlying trends and mean reversion are not driving our results.

Finally, we test whether next decade's change in population aging is associated with the current decade's economic growth. We replicate our main specification while including

$\ln \left(\frac{A_{s, t+20}}{N_{s, t+20}}\right)-\ln \left(\frac{A_{s, t+10}}{N_{s, t+10}}\right)$, the population aging "lead." Our instruments for this specification are the predicted population aging instrument (used for the main results) and also next decade's population aging instrument (i.e., the predicted aging lead). Because we cannot construct the population aging lead for the final decade in our data, we limit our analysis to 1980-2000. We first replicate our main estimate for this sample and present it in the first column of Appendix Table A.6. We estimate an elasticity of -0.83 for this sample. In Column 2, we also include the lead population aging instrument. If our instrument is correlated with confounding trends, then we would expect next decade's predicted aging to be negatively associated with economic growth. Instead, we find the opposite relationship. We estimate a small, positive, and statistically insignificant coefficient on the population aging lead variable. The estimate on the contemporaneous population aging measure increases in magnitude, suggesting that unobserved trends would potentially bias the main estimates towards zero, if at all.

\section{B.3. Robustness to Alternative Functional Form Assumptions}

Our main specification uses changes in the log of the older population share. To test whether this log specification is driving our results, we return to Appendix Table A.4. The bottom half of the table replicates the top half but uses levels instead of logs, instrumenting with the corresponding predicted level changes. As before, the point estimates on the change in the older share are similar regardless of whether other age groups are also included in the model. We estimate that each percentage point increase in the older share decreases GDP per capita by $2 \%$. Given that the mean older population share in the sample is 0.24 , a $10 \%$ increase in the older share implies a reduction in per capita GDP of $4.9 \%$ (using the estimate in the final column), which is similar to our main estimate.

Next, we estimate our model using Poisson regression. Santos Silva and Tenreyo (2006) show that a logged dependent variable in a linear regression restricts the error term. The 
specification in equation (1) assumes that the error term is multiplicative in per capita GDP growth. Using an exponential specification ${ }^{27}$ and estimating with Poisson regression relaxes this assumption, allowing for both multiplicative and additive error terms (also see Santos Silva and Tenreyo (2006) for advantages of Poisson over related estimators such a negative binomial regression). We replicate our main analysis using instrumental variables Poisson regression and present the results in Appendix Table A.7. We find similar results as before, further suggesting that our estimates are not driven by functional form assumptions.

\section{B.4. Robustness to Weighting and Outliers}

Appendix Table A.8 shows that the IV estimates are similar with and without weighting by state population size in the base year. Without weighting, we estimate a statistically significant effect of $4.8 \%$ in the pooled sample, compared to our main estimate of $5.5 \%$ with weighting. The point estimates for each decade estimated separately are negative, regardless of weighting. While we predict especially fast population aging in some states (e.g., Alaska), the inclusion or exclusion of these "outlier" states has little effect since they tend to be small. In related analyses, we estimate our main specification while dropping one state at a time. The elasticity estimates from this exercise vary between -0.659 and -0.449 and are always statistically significant from zero at the $5 \%$ level. These results are shown graphically in Appendix Figure A.3. Thus, our results are not driven by one particular state or outlier.

\section{B.5. Robustness to Common Regional Shocks, Mismeasurement of State of Residence}

In Appendix Table A.9 we show that our main estimates are robust to the inclusion of region-year interaction terms, and therefore common regional shocks are not driving our results. Appendix Table A.10 shows that the one-year misalignment in when residence is measured in the Census compared to state of residence in the previous year does not materially affect our estimates for the 2000-2010 period (the one period in which both the current and prior year's state of residence are available). The IV estimate increases in magnitude when we use the prior year's state of residence.

\footnotetext{
${ }^{27}$ Specifically, the specification is $\frac{G D P_{s, t+10}}{N_{s, t+10}}=\exp \left(\beta\left[\ln \left(\frac{A_{s, t+10}}{N_{s, t+10}}\right)-\ln \left(\frac{A_{s t}}{N_{s t}}\right)\right]+X_{s t}^{\prime} \delta_{t}+\gamma_{t}+\ln \left(\frac{G D P_{s, t}}{N_{s, t}}\right)\right) \eta_{s, t+10}$, where the coefficient on the log of per capita GDP in the original period is set to 1 .
} 


\section{Decomposing the Main Effect into Effects on Labor Productivity and Employment}

Our main estimate implies population aging slows economic growth to a significant degree. In this section, we investigate the underlying mechanisms using a sequence of decompositions. First, we decompose the slowdown in economic growth to determine the portion attributable to movements in labor supply versus labor productivity. Next, we test whether the effect of aging on labor productivity is matched by movements in the average wage (with and without accounting for fringe benefits). Last, we test whether aging-induced capital deepening has been sufficient to fully counteract the negative labor productivity effect.

Growth in log output per capita is the dependent variable in equation (1). We decompose output per capita $\left(G D P_{s t} / N_{s t}\right)$ using $\frac{G D P_{s t}}{N_{s t}}=\frac{G D P_{s t}}{\operatorname{Hours}_{s t}} \times \frac{\operatorname{Hours}_{s t}}{L_{s t}} \times \frac{L_{s t}}{N_{s t}}$, where $L$ represents the level of employment for workers ages 20+. Movements in log output per capita will be the sum of movements in log labor productivity, log hours worked per worker, and log employment per capita. It follows that the causal effect of population aging on these components must sum to the total effect of population aging on output growth (Hall and Jones, 1999; Wong, 2007; Feyrer, 2007). Thus, if we estimate equation (1) separately for each component of log output per capita (using the same IV specification as above), the component coefficients must sum to $\beta$ in equation (1). This decomposition technique allows us to examine the relative contribution of effects through the labor productivity and employment channels.

We present these decomposition estimates in Table 2. Column (1) reproduces our estimate of $\beta$, the total effect of population aging on growth in GDP per capita (from Table 1 Panel C). Column (2) presents the effect of population aging on growth in output per hour worked. Population aging has a substantial effect on growth in labor productivity: a 10\% increase in the fraction of the population $60+$ leads to a $3.4 \%$ decrease in GDP per hour worked. Population aging also decreases growth in the employment rate, as expected, but to a lesser degree than its impact on growth in labor productivity. Specifically, a $10 \%$ increase in the fraction of the population $60+$ leads to a $1.7 \%$ decrease in growth in employment per capita (Column 4). We observe little evidence of intensive labor supply effects (Column 3). ${ }^{28}$ The

\footnotetext{
${ }^{28}$ Similar to the analysis in Appendix Table A.4, we confirm that these results are not driven by omitting other age groups from the specification. These results are presented in Appendix Table A.11. The first outcome variable is growth in the log of GDP per hours worked and we instrument for each of the included age groups using predicted growth in their respective population shares; the effect of the older share is similar regardless of whether other age
} 
relative magnitudes of the coefficients indicate that about one-third of the total effect of population aging on economic growth operates through changes in employment per capita (extensive-margin labor supply), while the other two-thirds operates through changes in output per hour worked. The point estimates and conclusions are generally similar if we use longer instrument lag lengths. These results are provided in Table A.12.

We next investigate whether the aging-induced decline in labor productivity is matched by changes in labor compensation. Using the same approach as above, we decompose output per hour worked into the product of GDP per dollar of compensation and compensation per hour

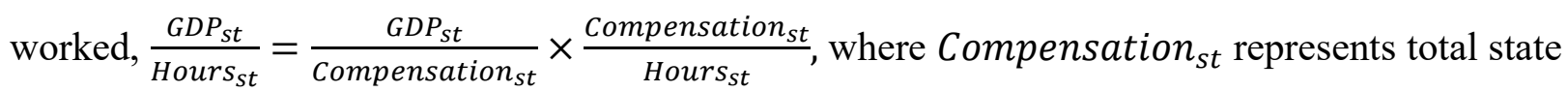
labor compensation in year $t$ using BEA's measure of total labor compensation (labor earnings plus non-cash compensation). If the effect of population aging on labor productivity growth reflects changes in the marginal product of labor, and if hourly compensation adjusts in response to changes in labor productivity, then the decline in labor productivity growth should be accompanied by a decline in hourly compensation and the effect of population aging on growth in GDP per compensation dollar should be zero. The findings in Table 3 support these hypotheses. A $10 \%$ increase in the fraction of the population $60+$ decreases compensation per hour by a statistically significant 3.3\% (Column 2, top panel), and decreases GDP per dollar earned by a statistically insignificant $0.1 \%$ (Column 1 , top panel). The estimates in Columns (1) and (2) sum to the estimate in Table 2, Column (2) by construction. We provide an alternative version of this decomposition in the bottom panel of Table 3, where instead of compensation per hour, we use earnings per hour ("wage"). We still observe a stronger effect on wage growth (Column 2) than GDP per dollar of labor earnings (Column 1), but the differences are less stark. These results for compensation and earnings reinforce our central finding that population aging has diminished labor productivity growth. To shed light on the precise productivity channels through which these effects operate, we next test for aging-induced movements in

groups are included in the model. The second outcome in this table is growth in hours per worker. Again, we find little evidence that the inclusion of other age groups affects the estimate on the $60+$ age group. The final outcome is growth in log employment per population aged $20+$. In this case, we see that growth in the population shares ages 30-39 and 40-49 has also reduced employment growth, but the effect of the older share is even larger when other age groups are included in the model. Taken together, the results suggest that although changes in the share of workers in these two younger age groups have contributed independently to the slowdown in employment growth, there was no corresponding effect on the decline in labor productivity growth. As before, the results are similar when estimated using age group shares in levels rather than logs (shown in bottom panel). 
physical capital. Data limitations make it impossible to separately identify the effects of population aging on human capital and technology. Drawing upon researcher-compiled data on the physical capital stock by state (government statistics on physical capital do not exist for U.S. states), ${ }^{29}$ we estimate equation (1) for growth in log physical capital per worker between 19802000 (these data do not extend to 2010). The estimated coefficient (standard error) on the older population share is $0.106(0.291)$ (see Appendix Table A.13). That is, a 10\% increase in the fraction of the population $60+$ leads to an increase in physical capital per worker of $1.1 \%$, but the estimate is not statistically significant. Nonetheless, the positive point estimate is suggestive of a modest, offsetting effect of aging-induced capital deepening between 1980-2000. The positive point estimate is also consistent with a small aging-induced increase in capital investment (Acemoglu and Restrepo, 2017). Regardless, the offsetting effect of capital deepening was not large enough to fully counteract the combined negative effects of aging on employment and labor productivity.

In conclusion, our decomposition analysis implies that about one-third of the total effect of population aging on economic growth operates through changes in employment per capita. The other two-thirds is due to changes in labor productivity. The reduction in labor productivity growth is matched by a reduction in hourly compensation growth, which points to the existence of labor market adjustments that compensate for real losses in labor productivity. We find suggestive evidence that physical capital deepening may have offset these losses to a modest degree.

\section{Spillover Effects on Younger Age Groups}

Workers in different age groups may be substitutes or complements to one another and therefore the productivity of one age group can depend on interactions with workers in other age groups. In this section, we examine the effects of population aging on the employment and earnings growth of individuals in different age groups to investigate the role of spillover effects from older to younger workers.

\footnotetext{
${ }^{29}$ Garofalo and Yamarik (2002) estimate state capital stock values to analyze convergence across states. These data were updated by Yamarik (2013) and used often in the literature studying cross-state capital stock variation (e.g., Peri, 2012; Reed, 2008; Han and Lee, 2016). Data are found here: https://web.csulb.edu/ $\sim$ syamarik/ (accessed November 15, 2017).
} 
We estimate equation (1) separately for ages 20-39, 40-59, and 60+. The dependent variable in each regression is the change in log employment per capita for the specified age group. As before, the key independent variable in all models is the change in the log fraction of population ages $60+$, for which we instrument as above. The two-stage least squares estimates are shown in Table 4. First, we find little effect of population aging on age-specific employment growth. The estimate for the 20-39 age group is 0.001. We estimate a negative and larger magnitude for the $60+$ age group of -0.074 , though the estimate is markedly less precise than those for the younger age groups and not statistically different from zero. While in Table 2 we observed evidence of overall reductions in the employment rate, we do not find strong evidence of reductions for any specific age group, suggesting that population aging induces lower growth in employment per capita by shifting a greater share of the population into older age groups with lower propensities to work.

In the second panel of Table 4, the outcome is the change in the log of the wage, defined as total labor earnings divided by total hours worked (by age group, state, and year). We estimate large losses in wage growth for the 60+ population: a $10 \%$ increase in the fraction of population ages $60+$ reduces wage growth for workers ages $60+$ by $3.4 \%$. This effect is consistent with productivity losses among older workers, including compositional shifts that might arise from older workers switching to less productive roles or occupations (e.g., bridge jobs) or the earlier retirement of relatively productive workers.

Third, we also estimate losses in wage growth for younger workers: population aging reduces wage growth for workers ages $40-59$ by $2.9 \%$ and workers $20-39$ by $1.7 \%$, though the latter estimate is not statistically different from zero. The reduction in wage growth for workers in younger age groups could arise from the loss of positive production spillovers from retiring older workers to their younger counterparts. ${ }^{30}$ This finding is consistent with Jäger and Heining (2019) who find the exogenous departure (unexpected death) of a high-skilled co-worker or manager results in a wage decrease for incumbent coworkers, pointing to a loss of positive productivity spillovers among complementary workers. Similarly, new evidence from Italy finds no effect on employment or firm productivity from a pension reform that resulted in delayed

\footnotetext{
30 The presence of negative wage growth effects across the age distribution is also consistent with efficiency losses arising from the "thinning" of labor markets in areas with faster population aging (Gan and Li, 2004).
} 
retirement of older workers (Carta et al. 2021). ${ }^{31}$ More generally, lower average productivity among older workers may affect younger groups if younger and older workers are complementary inputs in production, resulting in slower wage growth for both groups. Other mechanisms include the possibility that population aging induces less innovation, new business formation or the adoption of new technologies within existing businesses, impacting the productivity of all age groups. Recent research finds population aging leads to less entrepreneurship (Karahan et al. 2019, Liang et al. 2018, Bornstein 2020, Engbom 2019), which in turn slows productivity growth (Decker et al. 2017, Alon et al. 2018). ${ }^{32}$

While further research is needed to identify the precise mechanisms at work, our findings foretell a further slowdown in labor productivity growth reflecting not only compositional differences in the workforce but also real productivity losses among individuals across the age spectrum. At the same time, greater investment in human capital development throughout the lifecycle, greater utilization of labor-augmenting automation, and policies and practices that encourage employment at older ages could prevent these losses to some degree.

\section{Generalizability to the National Level}

Our estimates imply that differential population aging across U.S. states has led to important cross-state differences in economic growth. Extrapolating our estimates to explain or predict national trends requires additional considerations. An important advantage of our research design based on differential population aging across states in comparison to crosscountry designs is that it controls for common national shocks. An important disadvantage is that it omits the effects of any nationwide or federal policy response to population aging, which could either exacerbate or counteract the effects of population aging in aggregate. Ramey (2011) points out that state-based estimates of the fiscal multiplier of government spending will tend to overstate the multiplier because they cannot account for the offsetting effects of taxation required to finance the spending. Similarly, Bornstein (2020) shows how a model accounting for

\footnotetext{
${ }^{31}$ However, Bianchi et al. (2020) study the same Italian pension reform and find that delayed retirement of older workers results in a negative employment effect on younger workers with limited promotion opportunities in smaller firms.

${ }^{32}$ Appendix Table A.14 presents decadal estimates of the age-specific employment and wage effects of population aging, showing that the negative spillover effects were strongest in the 1980s when the employment rate of older individuals reached historical lows. Since then, the employment rate of older individuals has risen and the diffusion of technology has changed the skill demands of many jobs, potentially putting some older workers at a disadvantage.
} 
general equilibrium effects reduces the amount of the decline in the business startup rate explained by consumer inertia relative to the reduced-form model of variation across states.

In our setting, suppose the federal government raised the payroll tax rate or the Social Security taxable maximum in order to fund aging-related increases in Medicare expenditures or Social Security benefits. If all states were affected uniformly by the tax increase, then our estimates would understate the aggregate effect of population aging on economic growth since they would not capture the distortionary effect of the tax on labor supply, which would further slow economic growth. On the other hand, federal policies such as the ongoing scheduled increase in the Social Security full retirement age, the actuarial increase in the credit for delayed claiming of Social Security benefits, or the partial removal of the Social Security earnings test in 2000 , might have increased labor supply, ameliorating the effect of population aging on aggregate economic growth. Although our estimates miss the portion of any response to federal policy that is common across states, they do capture effects arising from the interaction of federal policy with aging-induced state economic conditions (e.g., an increase in the Social Security taxable maximum income level would affect states differently depending on the state income distribution induced by population aging). Similarly, our results do not account for aggregate general equilibrium effects (e.g., aging-induced changes in rates of return, asset prices, national debt) except to the extent they interact differentially with aging-driven state economic conditions.

Another issue in our context is that the effects of population aging at the state level may be exacerbated or ameliorated by the systematic reallocation of skills across states. An aging population, especially one that is aging in a predictable fashion, may induce higher skilled workers to relocate to a state that is aging more slowly. Since this behavior is in response to (predicted) aging, it is part of the causal effect that we capture (unlike changes in the elderly share due to confounding factors that also affect local economic growth). However, this type of migration is less likely to occur across countries than within countries, so its role is important to quantify before extrapolating the estimates to the national level.

To assess the migration response to population aging, we focus on two outcomes: (1) the size of the state population (as a measure of migration); and (2) the fraction of individuals with less than 4 years of college (as a measure of labor force skill). We present the estimates in Table 5. We find no statistical relationship between changes in the older share and changes in the log 
of the population size for the period as a whole or for any decade, indicating that migration does not react to state-level population aging. The point estimates are positive which is consistent with people migrating to states that are aging more rapidly.

Similarly, for the fraction of the adult population with less than 4 years of college, ${ }^{33}$ we estimate small and statistically insignificant effects of changes in the older share. Overall, we find little evidence of any systematic migration resulting from population aging which could either increase or decrease the magnitude of our results.

\section{Discussion and Conclusion}

The rapid aging of the U.S. population is expected to slow economic growth and place considerable strain on government entitlement programs. Noting that population aging has been long underway in the U.S., and that changes in the population age structure were largely predetermined by historical trends in the age structure, we use variation in the predicted rate of population aging across U.S. states as an instrumental variable to identify the impact of population aging on growth in state output per capita between 1980-2010. Over this time period and across states, we observe substantial variation in population aging, including aging rates comparable to rates forecasted for the U.S. as a whole in the near future.

Our estimate of the elasticity of per capita GDP growth with respect to population aging is -0.55 ; that is, a $10 \%$ increase in the fraction of the population ages $60+$ (equivalent to a $2.4 \mathrm{pp}$ increase in the older share) decreases growth in GDP per capita by $5.5 \%$. Our decompositions imply that $2 / 3$ of the total effect of population aging on growth in GDP per capita has arisen from slower labor productivity growth, while $1 / 3$ has been due to slower growth in employment per capita. Our analysis also suggests the slowdown in labor productivity growth was not fully offset by capital deepening or labor-augmenting technical change. The reduction in labor productivity growth was matched by a reduction in hourly compensation and wage growth that accrued to younger workers as well as older workers, indicating the labor productivity slowdown was broad based. Such widespread impacts could arise from productivity externalities across age groups or from slowing rates of innovation and entrepreneurship.

\footnotetext{
${ }^{33}$ The Census does not measure college degree status consistently across our sample period.
} 
Most studies in the literature have concluded the relationship between population aging and economic outcomes is negative. For example, Sheiner et al. (2007) and Sheiner (2014) calculated the downward consumption adjustments required (now or later) to offset the negative effects of population aging on output per person. Gagnon et al. (2021) attributed the entire decline in real GDP growth since 1980 to population aging. Nonetheless, the emphasis in this literature has been on the labor force growth channel (e.g., Aaronson et al., 2006, Aaronson et al., 2014); it was not expected that population aging would also reduce labor productivity growth (National Research Council 2012; Fernald and Jones 2014; Fernald, 2016; Gordon 2016). As a representative example, the National Research Council (2012) predicted a slowdown in growth in GDP per capita of $0.33-0.55$ pp per year relative to the long-run rate of $1.88 \%$ between 2010 2050 , arising entirely from slowing labor force growth with no change in labor productivity. Our elasticity for growth in employment per capita alone implies an annual reduction in GDP per capita growth similar to their estimate of the total effect of population aging.

Only a handful of studies have considered the labor productivity channel. Feyrer (2007, 2008) found total factor productivity growth decreased as the share of workers who were ages 50+ rose in OECD and low-income countries between 1960 and 1990 ${ }^{34}$ and Aiyar et al. (2016) concluded the share of workers ages 55-64 reduced labor productivity growth in Europe between 1950 to 2014, primarily through its negative effect on total factor productivity. ${ }^{35}$

Other influential studies have emphasized the possibility of offsetting effects arising from economic responses to labor scarcity. Cutler et al. (1990) documented positive correlations between population aging, per capita output growth, and productivity growth across OECD countries between 1960-1985, arguing that although slowing labor force growth puts downward pressure on growth in output per capita, it may also trigger capital deepening and/or technical change sufficient to offset that pressure. Acemoglu and Restrepo (2017) illustrate the technical change mechanism by deriving theoretical conditions under which the relative scarcity of labor could trigger capital investments in automation; they document a positive relationship between workforce aging (defined as the ratio of older to younger workers) and growth in output per capita in 169 countries between 1990-2015. But, importantly, Eggertsson et al. (2019) show the

\footnotetext{
${ }^{34}$ Feyrer (2008) also estimated models of changes in wage growth on changes in the age distribution of the workforce at the state and metropolitan levels using U.S. data.

${ }^{35}$ In addition, Daniele et al. (2020) estimate the effect of the ratio of older to young workers across small regions in the OECD. They find evidence of reductions in productivity growth, predominantly in urban areas.
} 
positive empirical relationship turns negative in settings where aging-induced capital deepening does not occur. ${ }^{36}$ Börsch-Supan (2003) noted in the context of Germany that capital deepening was unlikely to be large enough to offset the negative effects of aging on economic growth. ${ }^{37}$

Extrapolating our elasticities to the national level offers insight into the historical and potential future impacts of population aging on growth in national GDP per capita. Between 1980 and 2010, the older share increased by $16.8 \%$ in the United States. Thus, our estimate implies that per capita GDP over the same time period was $9.2 \%$ lower - a cumulative loss of 7.4 pp over the 30-year period - than it otherwise would have been absent population aging. ${ }^{38}$ Annualizing this rate, this decrease corresponds to a decline in the annual rate of growth of 0.3 pp per year over a time period when the average annual growth rate was $1.88 \mathrm{pp}$.

Over 2010-2020, the older population share rose $21 \%$. Our estimates imply that population aging accounted for an average loss of $1.2 \mathrm{pp}$ per year during this time period. Demographic projections suggest that, between 2020-2030, the older population share will rise by $11 \%$. Our results, therefore, imply a potential reduction in annual growth of 0.6 pp per year due to population aging over the next decade.

An important limitation of our estimates is that they do not account for aggregate effects that accrue uniformly across the nation. ${ }^{39}$ Population aging may trigger federal policy or aggregate general equilibrium effects that cannot be captured in a state-based research design, except to the extent they interact differentially with state economic conditions. As a result, our estimates do not preclude even larger effects of population aging on per-capita economic growth in the United States in the coming decades. On the other hand, further improvements in human capital and investments in labor-augmenting technologies, coupled with greater labor force participation at older ages could temper these effects, as well as reduce the magnitude of changes in federal policy that will be required to address them.

\footnotetext{
${ }^{36}$ Such was the case in the U.S. and other OECD countries between 2008-2015, when low interest rates have been unable to adjust downward to equate investment and savings (Eggertsson et al. 2019).

${ }^{37}$ In a similar vein, Vogel et al. (2017) calibrate an overlapping generations model that assumes capital deepening will increase human capital investment leading to increased labor productivity.

${ }^{38}$ Per capita GDP increased by $72.8 \%$ from 1980 to 2010 . Authors' calculations using Federal Reserve Economic Data (https://fred.stlouisfed.org/series/A939RX0Q048SBEA) on real GDP per capita for July 1, 1980 and July 1, 2010.

39 The National Research Council also did not account for general equilibrium effects of population aging on the federal budget that might lead to changes in tax policy, so this is not a source of difference between our estimate and their forecast.
} 


\section{References}

Aaronson, S., Fallick, B., Figura, A. Pingle, J., and Wascher, W.L. (2006). "The Recent Decline in Labor Force Participation and its Implications for Potential Labor Supply." Brookings Papers on Economic Activity, 1:2006.

Aaronson, S., Cajner, T., Fallick, B., Galbis-Reig, F., Smith, C. and Wascher, W., 2014. Labor force participation: recent developments and future prospects. Brookings Papers on Economic Activity, 2014(2), pp.197-275.

Acemoglu, D. and Restrepo, P. (2017). Secular stagnation? The effect of aging on economic growth in the age of automation. American Economic Review, 107(5), pp.174-79.

Administration on Aging (2014). "Projected Future Growth of the Older Population." U.S. Department of Health and Human Services.

http://www.aoa.gov/Aging_Statistics/future_growth/future_growth.aspx (accessed on October 3, 2014).

Alon, T., Berger, D., Dent, R., \& Pugsley, B. (2018). Older and slower: The startup deficit's lasting effects on aggregate productivity growth. Journal of Monetary Economics, 93, 68-85.

Aiyar, Shekhar, Christian Ebeke, and Xiaobo Shao (2016). "The Impact of Workforce Aging on European Productivity.” International Monetary Fund Working Paper 16/238.

Aksoy, Yunus, Henrique S. Basso, Tobias Grasl and Ron P. Smith (2015). "Demographic Structure and Macroeconomic Trends," Manuscript, available on REPEC https://ideas.repec.org/p/bbk/bbkefp/1501.html.

Barro, Robert J and Xavier Sala-i-Martin (1992). “Convergence.” Journal of Political Economy, 100(2), 223-251.

Bartik, Timothy J (1991). Who Benefits from State and Local Economic Development Policies? Kalamazoo, MI: W.E. Upjohn Institute for Employment Research.

Bianchi, N., Bovini, G., Li, J., Paradisi, M., \& Powell, M. L. (2021). “Career spillovers in internal labor markets.” National Bureau of Economic Research Working Paper No. w28605.

Blanchard, Oliver Jean and Lawrence F. Katz (1992). "Regional Evolutions.” Brookings Papers on Economic Activity, 1992(1): 1-75.

Bloom, David, David Canning, and Jaypee Sevilla (2003). The demographic dividend: A new perspective on the economic consequences of population change. RAND Corporation.

Bornstein, Gideon (2020). Entry and Profits in an Aging Economy: The Role of Consumer Inertia. Mimeo.

Börsch-Supan, Axel (2003). "Labor market effects of population aging." Labour 17.s1: 5-44.

Borusyak, K., Hull, P. and Jaravel, X. (2021). Quasi-experimental Shift-share Research

Designs. Review of Economic Studies, forthcoming.

Bureau of Economic Analysis (2006). "Gross Domestic Product by State Estimation Methodology." U.S. Department of Commerce.

http://www.bea.gov/regional/pdf/gsp/GDPState.pdf (accessed October 1, 2014). 
Carta, F., D'Amuri, F., \& von Wachter, T. M. (2021). Workforce aging, pension reforms, and firm outcomes. National Bureau of Economic Research Working Paper No. w28407.

Cutler, D. M., Poterba, J. M., Sheiner, L. M., Summers, L. H., \& Akerlof, G. A. (1990). An aging society: opportunity or challenge? Brookings Papers on Economic Activity, 1-73.

Daniele, F., Honiden, T. and Lembcke, A.C. (2020). Ageing and productivity growth in OECD regions: Combatting the economic impact of ageing through productivity growth? In Ageing and Fiscal Challenges Across Levels of Government.

Decker, R., Haltiwanger, J., Jarmin, R., \& Miranda, J. (2014). The role of entrepreneurship in US job creation and economic dynamism. Journal of Economic Perspectives, 28(3), 3-24.

Engbom, N. (2019). Firm and worker dynamics in an aging labor market (No. 756, pp. 1-58). Federal Reserve Bank of Minneapolis.

Eggertsson, G.B., Lancastre, M. and Summers, L.H. (2019). Aging, output per capita and secular stagnation. AER Insights, 1(3):325-342.

Fernald, John G. (2016). “Reassessing Longer-Run U.S. Growth: How Low?” Federal Reserve Bank of San Francisco Working Paper Series.

Fernald, J.G. and Jones, C.I. (2014). The future of US economic growth. American Economic Review, 104(5), pp.44-49.

Feyrer, James (2007). "Demographics and productivity." The Review of Economics and Statistics 89, no. 1: 100-109.

Feyrer, James (2008). "Aggregate evidence on the link between age structure and productivity." Population and Development Review, pp. 78-99.

Gagnon, Etienne, Benjamin Kramer Johannsen, and J. David Lopez-Salido (2021).

"Understanding the New Normal: The Role of Demographics." IMF Economic Review, 69, 357390.

Gan, Li and Qi Li (2004). "Efficiency of Thin and Thick Labor Markets.” NBER Working Paper No. 10815.

Garofalo, G. A., \& Yamarik, S. (2002). Regional convergence: Evidence from a new state-bystate capital stock series. Review of Economics and Statistics, 84(2), 316-323.

Goldsmith-Pinkham, P., Sorkin, I. and Swift, H. (2020). Bartik Instruments: What, When, Why, and How. American Economic Review, 110(8), 2586-2624.

Gordon, R. J. (2016). The Rise and Fall of American Growth : The U.S. Standard of Living Since the Civil War. Princeton: Princeton University Press (The Princeton Economic History of the Western World). Available at: http://search.ebscohost.com.ezpprod1.hul.harvard.edu/login.aspx?direct $=$ true $\& d b=$ nlebk\&AN $=1067515 \&$ site $=$ ehostlive\&scope $=$ site (Accessed: 8 June 2021).

Hall, Robert E. and Jones, Charles I. (1999). Why Do Some Countries Produce So Much More Output Per Worker Than Others? The Quarterly Journal of Economics, 114(1), 83-116.

Han, X., \& Lee, L. F. (2016). Bayesian Analysis of Spatial Panel Autoregressive Models With Time-Varying Endogenous Spatial Weight Matrices, Common Factors, and Random Coefficients. Journal of Business \& Economic Statistics, 34(4), 642-660. 
Jäger, Simon and Jörg Heining (2019). How Substitutable Are Workers? Evidence from Worker Deaths. MIT, Mimeo.

Jaimovich, Nir and Henry E. Siu (2009). The young, the old, and the restless: Demographics and business cycle volatility. The American Economic Review, 99(3), 804-826.

Karahan, F., Pugsley, B., \& Şahin, A. (2019). Demographic origins of the startup deficit. National Bureau of Economic Research Working Paper No. w25874.

Karahan, Fatih and Serena Rhee (2014). "Population Aging, Migration Spillovers, the Decline in Interstate Migration.” Federal Reserve Bank of New York Staff Report No. 699.

Kögel, Tomas (2005). "Youth dependency and total factor productivity." Journal of Development Economics 76, no. 1: 147-173.

Kozeniauskas, N. (2017). What's driving the decline in entrepreneurship. New York University, Mimeo.

Liang, J., Wang, H., \& Lazear, E. P. (2018). Demographics and entrepreneurship. Journal of Political Economy, 126(S1), S140-S196.

Maestas, Nicole, Kathleen J. Mullen and David Powell. "The Effect of Local Labor Demand Conditions on the Labor Supply Outcomes of Older Americans." RAND Working Paper \#WR1019, October 2013.

Nakamura, E., \& Steinsson, J. (2014). Fiscal stimulus in a monetary union: Evidence from US regions. American Economic Review, 104(3), 753-92.

National Research Council of the National Academies (2012). Aging and the Macroeconomy: Long-Term Implications of an Older Population. Washington, D.C.: The National Academies Press.

Peri, G. (2012). The effect of immigration on productivity: Evidence from US states. Review of Economics and Statistics, 94(1), 348-358.

Ramey, V.A. (2011). Can government purchases stimulate the economy? Journal of Economic Literature, 49(3), pp.673-85.

Reed, W. R. (2008). The robust relationship between taxes and US state income growth. National Tax Journal, 57-80.

Ruggles, Steven, Katie Genadek, Ronald Goeken, Josiah Grover, and Matthew Sobek (2015). Integrated Public Use Microdata Series: Version 6.0 [Machine-readable database]. Minneapolis: University of Minnesota.

Salgado, S. (2020). Technical change and entrepreneurship. Available at SSRN 3616568.

Santos Silva, JMC, and Silvana Tenreyro (2006). "The log of gravity." The Review of Economics and Statistics 88, no. 4: 641-658.

Sheiner, Louise, Daniel Sichel, and Lawrence Slifman (2007). "A Primer on the Macroeconomic Implications of Population Aging." The Federal Reserve Board Finance and Economics Discussion Series 2007-1.

Sheiner, Louise. (2014). The Determinants of the Macroeconomic Implications of Aging. The American Economic Review, 104(5), 218-223. 
Shimer, R. (2001). "The Impact of Young Workers on the Aggregate Labor Market." Quarterly Journal of Economics, 116(3): 969-1007.

Vogel, E., Ludwig, A., \& Börsch-Supan, A. (2017). “Aging and pension reform: extending the retirement age and human capital formation" Journal of Pension Economics and Finance, 16(01): 81-107.

Wong, W. K. (2007). Economic Growth: A Channel Decomposition Exercise. The B.E. Journal of Macroeconomics: Topics. Volume 1, Article 4.

Yamarik, S. (2013). State-Level Capital and Investment: Updates and Implications.

Contemporary Economic Policy, 31(1), pp.62-72. 


\section{Figures}

Figure 1: Percent of United States Population Age 60+: Actual and Projected - 1900-2050

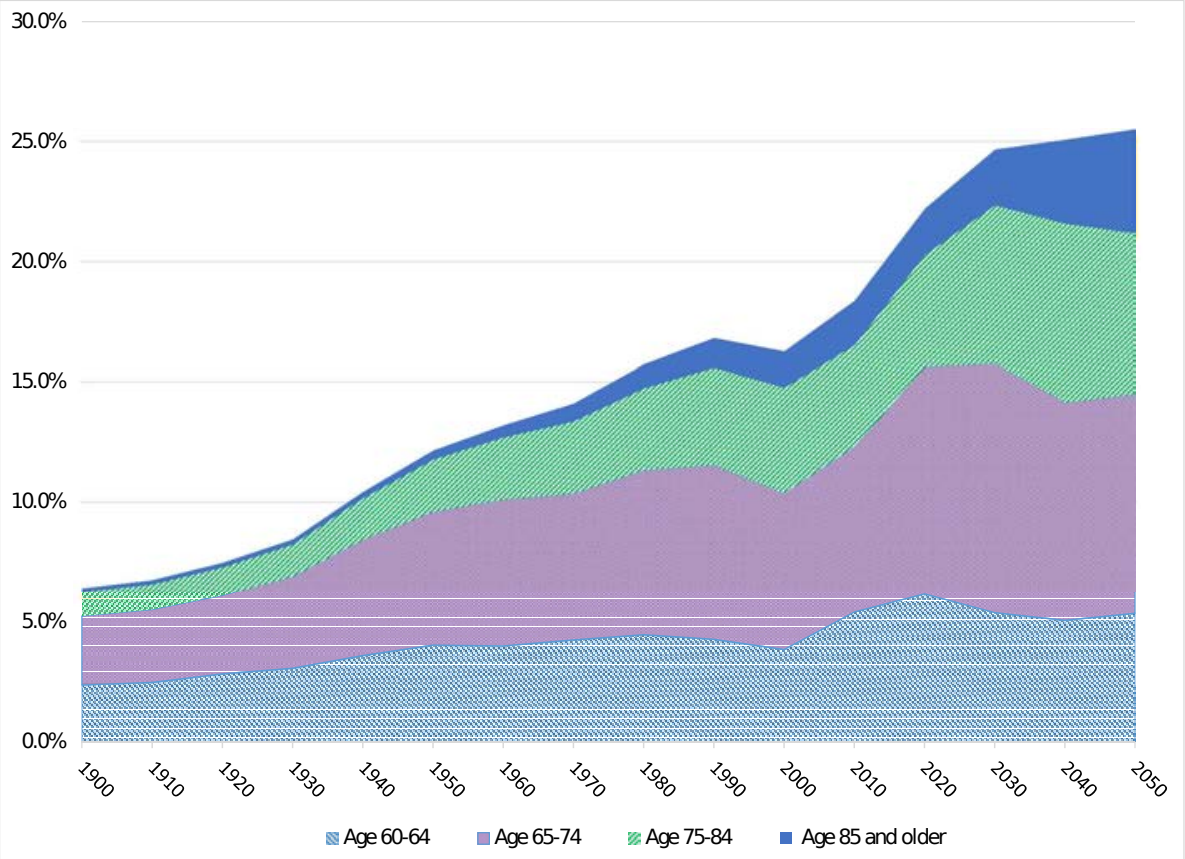

Source: U.S. Census Bureau, compiled by U.S. Administration on Aging (2014). 
Figure 2: Relationships between Aging, Predicted Aging, and Economic Growth

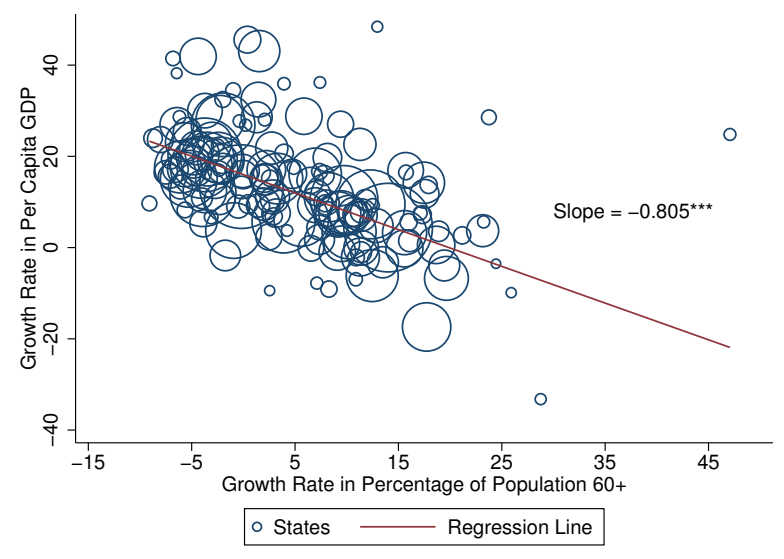

A. Aging and Per Capita GDP Growth

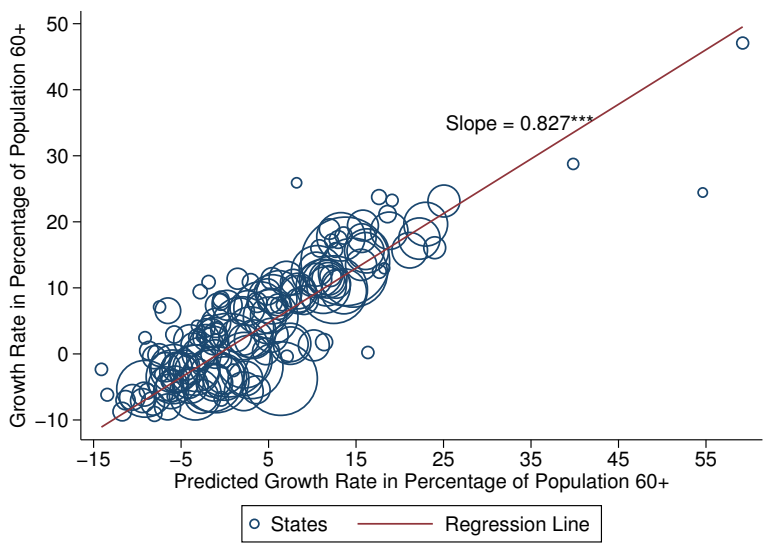

B. Predicted Aging and Observed Aging

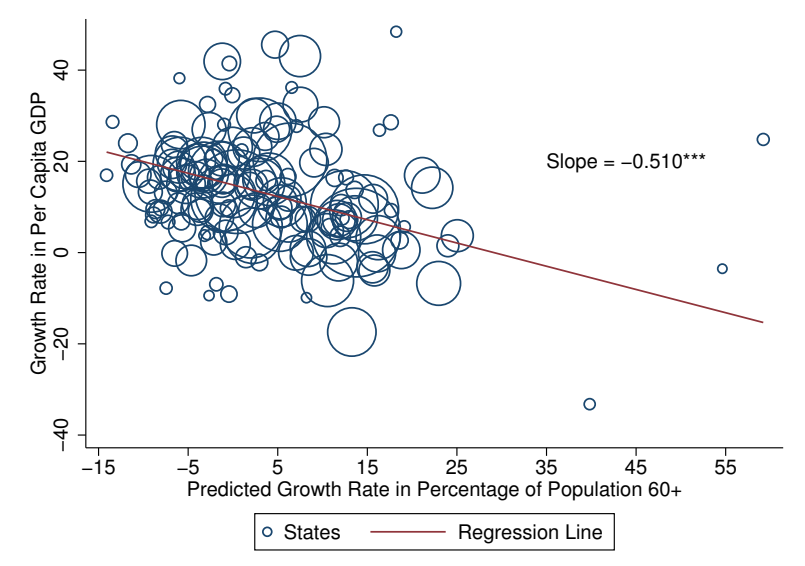

\section{Predicted Aging and Per Capita GDP \\ Growth}

Notes: Number of observations in each figure $=153$. Size of bubbles reflects state population size. The predicted growth rate of the percentage of the population ages 60+ is based on the 10-year lag instrument. We use 1980-2010 data. Each point represents a 10 year growth rate (in real terms). 


\section{Tables}

Table 1: Main Results by Instrument Lag

\begin{tabular}{|c|c|c|c|c|}
\hline Panel A: & \multicolumn{4}{|c|}{ Reduced Form Estimates } \\
\hline Dependent Variable: & \multicolumn{4}{|c|}{$\Delta \ln (\mathrm{GDP} / \mathrm{N})$} \\
\hline \multirow{3}{*}{$\Delta \ln \left(\frac{\hat{A}}{\hat{N}}\right)$} & 10 Year Lag & 20 Year Lag & 30 Year Lag & 40 Year Lag \\
\hline & $\overline{-0.390 * * *}$ & $\overline{-0.312^{* *}}$ & $-0.310^{*}$ & -0.248 \\
\hline & $(0.134)$ & $(0.126)$ & $(0.160)$ & $(0.172)$ \\
\hline Panel B: & \multicolumn{4}{|c|}{ First Stage Estimates } \\
\hline Dependent Variable: & \multicolumn{4}{|c|}{$\Delta \ln (\mathrm{A} / \mathrm{N})$} \\
\hline \multirow{3}{*}{$\Delta \ln \left(\frac{\hat{A}}{\hat{N}}\right)$} & 10 Year Lag & 20 Year Lag & 30 Year Lag & 40 Year Lag \\
\hline & $0.716^{* * *}$ & $0.621^{* * *}$ & $0.689 * * *$ & $0.457^{* * *}$ \\
\hline & $(0.054)$ & $(0.062)$ & $(0.074)$ & $(0.127)$ \\
\hline First Stage F-Statistic & 174.24 & 103.47 & 85.07 & 13.02 \\
\hline Panel C: & \multicolumn{4}{|c|}{ Instrumental Variable Estimates } \\
\hline Dependent Variable: & \multicolumn{4}{|c|}{$\Delta \ln (\mathrm{GDP} / \mathrm{N})$} \\
\hline \multirow{3}{*}{$\Delta \ln \left(\frac{A}{N}\right)$} & 10 Year Lag & 20 Year Lag & 30 Year Lag & 40 Year Lag \\
\hline & $-0.545^{* * *}$ & $-0.503^{* * *}$ & $-0.450^{* *}$ & -0.543 \\
\hline & $(0.173)$ & $(0.184)$ & $(0.214)$ & $(0.325)$ \\
\hline
\end{tabular}

Notes: Significance Levels: $* 10 \%, * * 5 \%, * * * 1 \%$. Num. Obs. $=153$ in all regressions. Standard errors in parentheses adjusted for clustering at state level. Each observation is weighted by period $t$ population. $\Delta y \equiv y_{s, t+10}-y_{s t}$. Other variables included: year dummies; the log of the fraction of workers in the applicable initial period (i.e., period $t$ ) working in each of the following industries: agriculture, mining, construction, manufacturing, transportation, communications / utilities, wholesale trade, retail trade, finance / insurance / real estate, business and repair services, personal services, recreation services, professional services, and public administration. The industry composition variables are interacted with the time dummies to allow the effects of initial industry composition to vary by year. 
Table 2: Decomposing Main Effect

$(1)$

(2)

10 Year Lag

(3)

(4)

Instrument Length:

\begin{tabular}{ccccc}
\hline Dependent Variable: & $\Delta \ln (\mathrm{GDP} / \mathrm{N})$ & $\Delta \ln (\mathrm{GDP} / \mathrm{Hours})$ & $\Delta \ln (\mathrm{H} / \mathrm{L})$ & $\Delta \ln (\mathrm{L} / \mathrm{N})$ \\
$\Delta \ln \left(\frac{A}{N}\right)$ & $-0.545^{* * *}$ & $-0.343^{* *}$ & -0.031 & $-0.172^{* * *}$ \\
& $(0.173)$ & $(0.151)$ & $(0.033)$ & $(0.047)$ \\
\hline
\end{tabular}

Notation: $\mathrm{L}=$ number of workers; Hours = total number of hours worked

Notes: Significance Levels: $* 10 \%, * * 5 \%, * * * 1 \%$. Num. Obs. $=153$ in all regressions. Standard errors in parentheses adjusted for clustering at state level. Each observation is weighted by period $t$ population. $\Delta y \equiv y_{s, t+10}-y_{s t}$. The coefficients presented in Columns (2), (3), and (4) mechanically sum to the main effect presented in Column (1). Other variables included: year dummies; the log of the fraction of workers in the applicable initial period (i.e., period $t$ ) working in each of the following industries: agriculture, mining, construction, manufacturing, transportation, communications / utilities, wholesale trade, retail trade, finance / insurance / real estate, business and repair services, personal services, recreation services, professional services, and public administration. The industry composition variables are interacted with the time dummies to allow the effects of initial industry composition to vary by year. We estimate using 2SLS.

Table 3: Decomposing the Productivity Effect

\begin{tabular}{ccc}
\hline & \multicolumn{2}{c}{ Decomposing $\Delta \ln ($ GDP $/$ Hours $)$} \\
& $(1)$ & $(2)$ \\
\hline Dependent Variable: & $\Delta \ln ($ GDP/Compensation $)$ & $\Delta \ln$ (Compensation/Hours $)$ \\
\cline { 2 - 3 }$\Delta \ln \left(\frac{A}{N}\right)$ & -0.011 & $-0.331^{* * *}$ \\
Num. Obs. & $(0.108)$ & $(0.123)$ \\
\hline Dependent Variable: & 153 & 153 \\
$\Delta \ln \left(\frac{A}{N}\right)$ & $\Delta \ln ($ GDP $/$ Earnings $)$ & $\Delta \ln ($ Earnings/Hours $)$ \\
Num. Obs. & -0.145 & $-0.197^{*}$ \\
& $(0.112)$ & $(0.113)$ \\
\hline
\end{tabular}

Notation: Hours $=$ total number of hours worked; Earnings $=$ total labor earnings; Compensation $=$ total compensation paid to workers.

Notes: Significance Levels: $* 10 \%, * * 5 \%, * * * 1 \%$. Standard errors in parentheses adjusted for clustering at state level. Each observation is weighted by period $t$ population. $\Delta y \equiv y_{s, t+10}-y_{s t}$. The coefficients in Columns (1) and (2) mechanically add up to the effect estimated in Column (2) of Table 2. Other variables included: year dummies; the $\log$ of the fraction of workers in the applicable initial period (i.e., period $t$ ) working in each of the following industries: agriculture, mining, construction, manufacturing, transportation, communications / utilities, wholesale trade, retail trade, finance / insurance / real estate, business and repair services, personal services, recreation services, professional services, and public administration. The industry composition variables are interacted with the time dummies to allow the effects of initial industry composition to vary by year. We estimate using 2SLS with the 10 year lagged instrument. 
Table 4: Age-Specific Labor Outcomes

\begin{tabular}{cccc}
\hline Outcome: & \multicolumn{3}{c}{$\Delta \ln ($ Employment Rate $)$} \\
\hline Age Group: & $\underline{20-39}$ & $\underline{40-59}$ & $\underline{60+}$ \\
$\Delta \ln \left(\frac{A}{N}\right)$ & $\begin{array}{c}0.001 \\
(0.040)\end{array}$ & $\begin{array}{c}-0.011 \\
(0.039)\end{array}$ & $\begin{array}{c}-0.074 \\
(0.143)\end{array}$ \\
\hline Outcome: & \multicolumn{3}{c}{$\Delta \ln ($ Wage $)$} \\
\hline Age Group: & $\underline{20-39}$ & $\underline{40-59}$ & $\underline{60+}$ \\
$\Delta \ln \left(\frac{A}{N}\right)$ & -0.165 & $-0.291^{* *}$ & $-0.341^{* * *}$ \\
& $(0.123)$ & $(0.120)$ & $(0.120)$ \\
\hline
\end{tabular}

Notes: Significance Levels: $* 10 \%, * * 5 \%, * * * 1 \%$. Number of observations $=153$. Standard errors in parentheses adjusted for clustering at state level. Each observation is weighted by period $t$ population. $\Delta y \equiv y_{s, t+10}-y_{s t}$. The outcome is the log of the number of people working scaled by the total number of people (by age group) or the log of the average wage (total earnings scaled by total hours). Other variables included: year dummies; the log of the fraction of workers in the applicable initial period (i.e., period $t$ ) working in each of the following industries: agriculture, mining, construction, manufacturing, transportation, communications / utilities, wholesale trade, retail trade, finance / insurance / real estate, business and repair services, personal services, recreation services, professional services, and public administration. The industry composition variables are interacted with the time dummies to allow the effects of initial industry composition to vary by year. We estimate using 2SLS with the 10 year lagged instrument. 
Table 5: Testing for Reallocation of Skills

\begin{tabular}{ccccc}
\hline Dependent Variable: & \multicolumn{4}{c}{$\Delta \ln$ (Population) } \\
\hline$\Delta \ln \left(\frac{A}{N}\right)$ & $\frac{1980-2010}{0.150}$ & $\frac{1980-1990}{0.353}$ & $\frac{1990-2000}{0.382}$ & $\frac{2000-2010}{0.007}$ \\
Num. Obs. & $(0.194)$ & $(0.414)$ & $(0.867)$ & $(0.133)$ \\
& 153 & 51 & 51 & 51 \\
\hline Dependent Variable: & $\Delta \ln ($ Fraction with Less & Than 4 Years College) \\
\hline$\Delta \ln \left(\frac{A}{N}\right)$ & $\underline{1980-2010}$ & $\frac{1980-1990}{19019}$ & $\frac{1990-2000}{2000-2010}$ & $\frac{-0.082}{0.030}$ \\
Num. Obs. & $(0.054)$ & $(0.057)$ & $(0.177)$ & $(0.046)$ \\
\hline
\end{tabular}

Notes: Significance Levels: ${ }^{*} 10 \%, * * 5 \%, * * * 1 \%$. Standard errors in parentheses adjusted for clustering at state level. Each observation is weighted by period $t$ population. $\Delta y \equiv y_{s, t+10}-y_{s t}$. Other variables included: year dummies; the log of the fraction of workers in the applicable initial period (i.e., period $t$ ) working in each of the following industries: agriculture, mining, construction, manufacturing, transportation, communications / utilities, wholesale trade, retail trade, finance / insurance / real estate, business and repair services, personal services, recreation services, professional services, and public administration. The industry composition variables are interacted with the time dummies to allow the effects of initial industry composition to vary by year. We estimate using 2SLS with the 10 year lagged instrument. 


\section{Appendix: For Online Publication Only}

Figure A.1A: Growth Rate in Age 60+ Population by State: 1980-1990

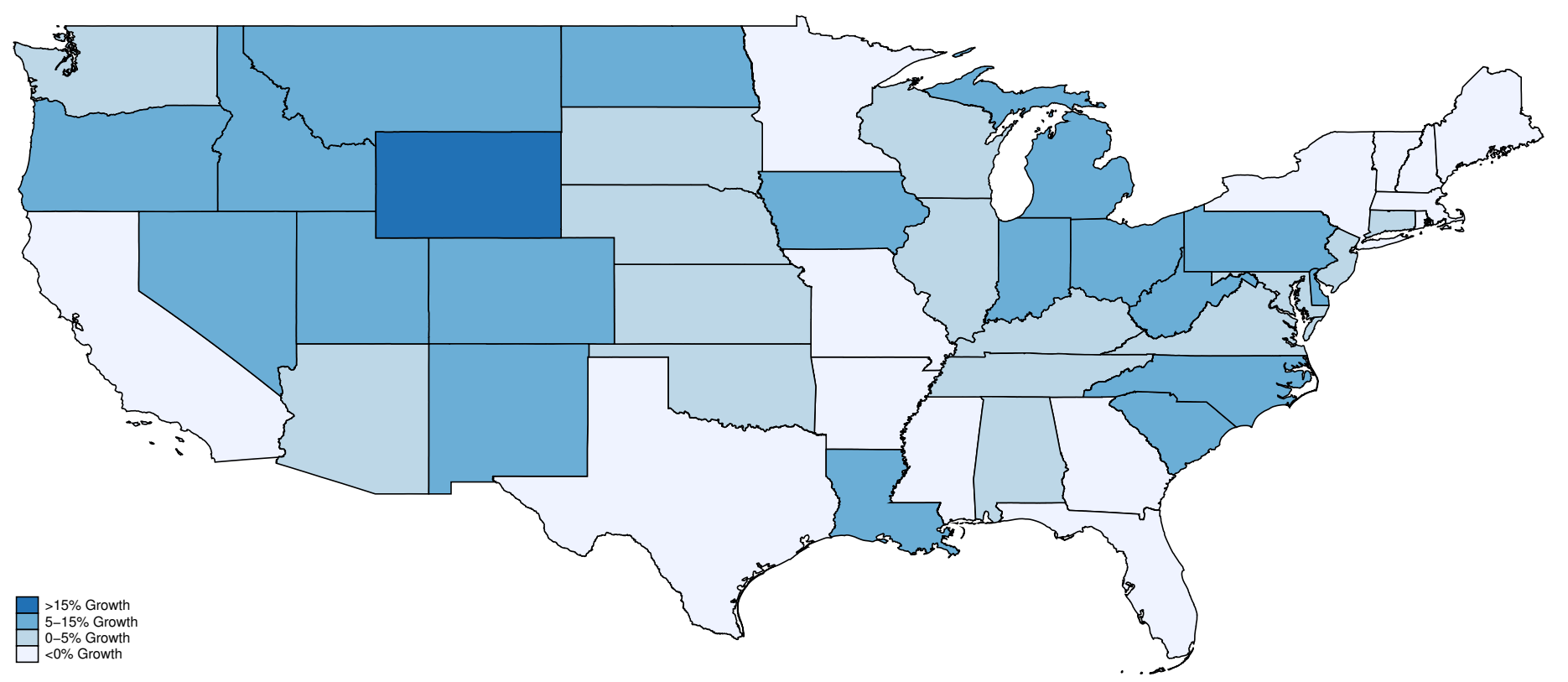

Notes: We use 1980 and 1990 Census data to construct the fraction of each state's population ages $60+$. This map refers to the percentage change in this metric between 1980 and 1990. 
Figure A.1B: Growth Rate in Age 60+ Population by State: 1990-2000

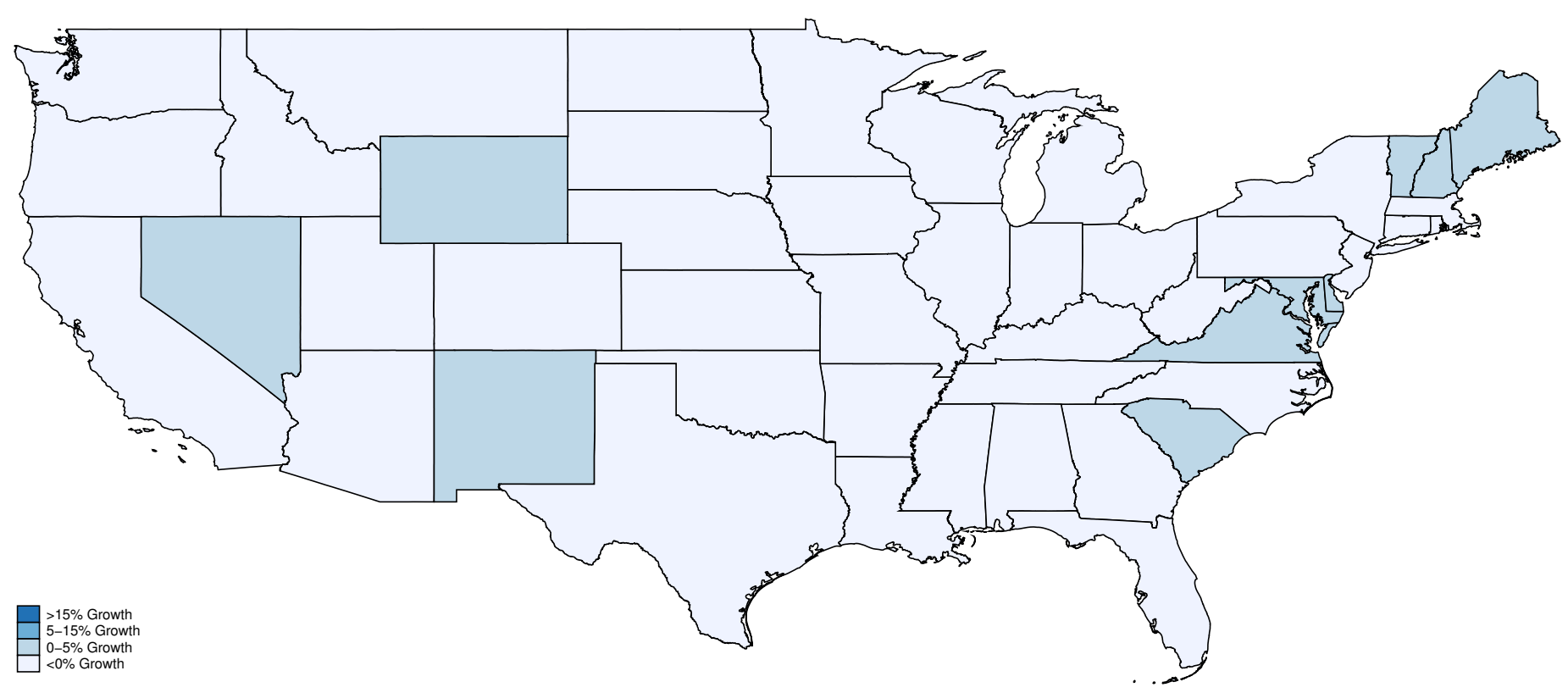

Notes: We use 1990 and 2000 Census data to construct the fraction of each state's population ages 60+. This map refers to the percentage change in this metric between 1990 and 2000.

Figure A.1C: Growth Rate in Age 60+ Population by State: 2000-2010

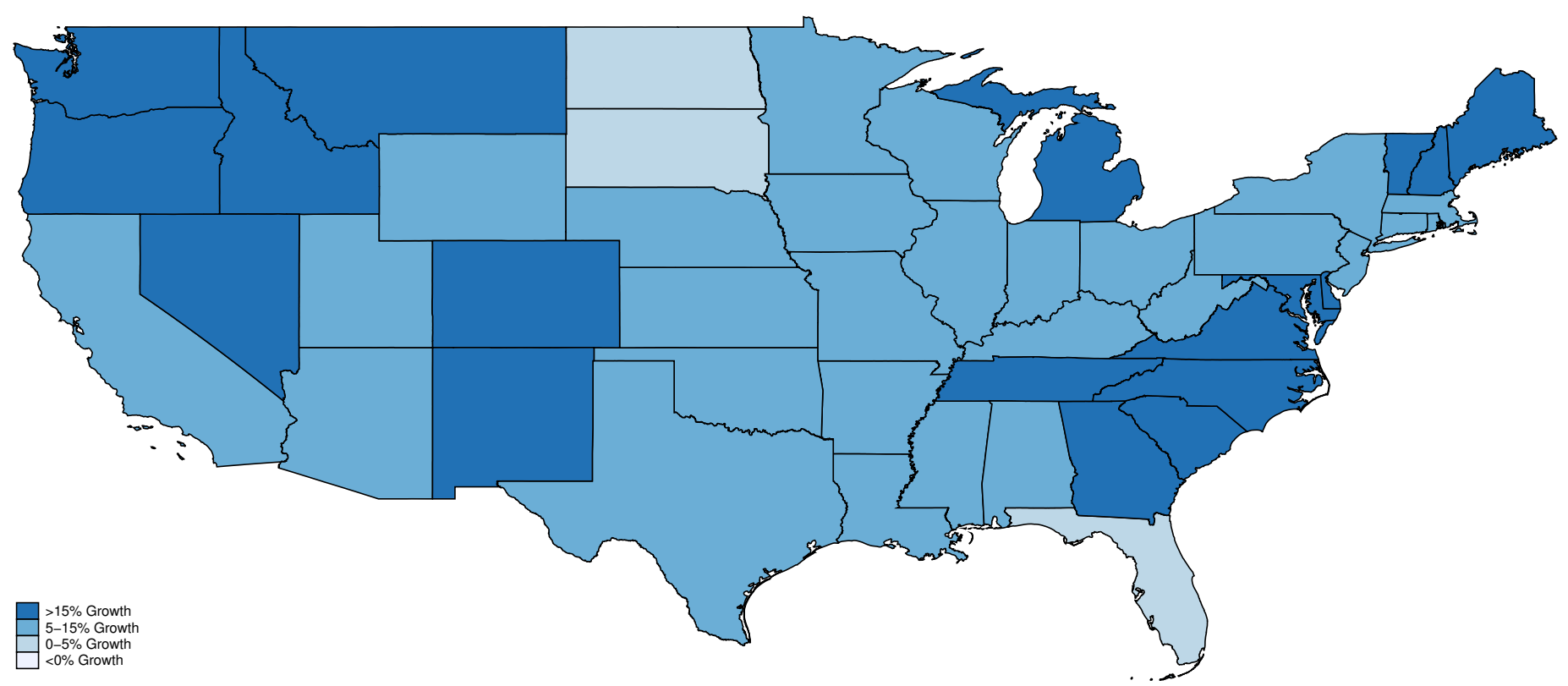

Notes: We use 2000 and 2010 Census data to construct the fraction of each state's population ages $60+$. This map refers to the percentage change in this metric between 2000 and 2010 . 
Figure A.2A: Growth Rate in Real Per Capita GDP by State: 1980-1990

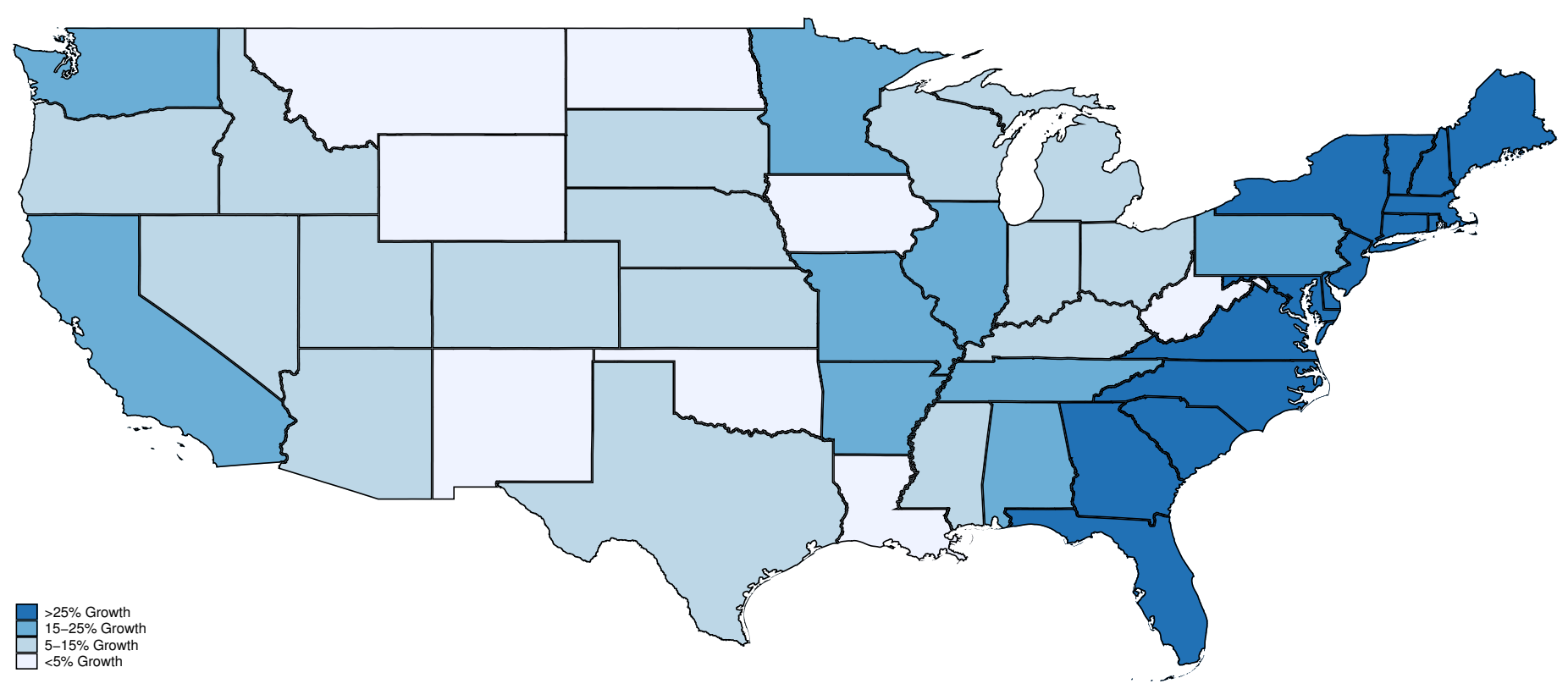

Notes: We use 1980 and 1990 BEA data to construct per capita GDP. This map refers to the percentage change in real terms between 1980 and 1990.

Figure A.2B: Growth Rate in Real Per Capita GDP by State: 1990-2000

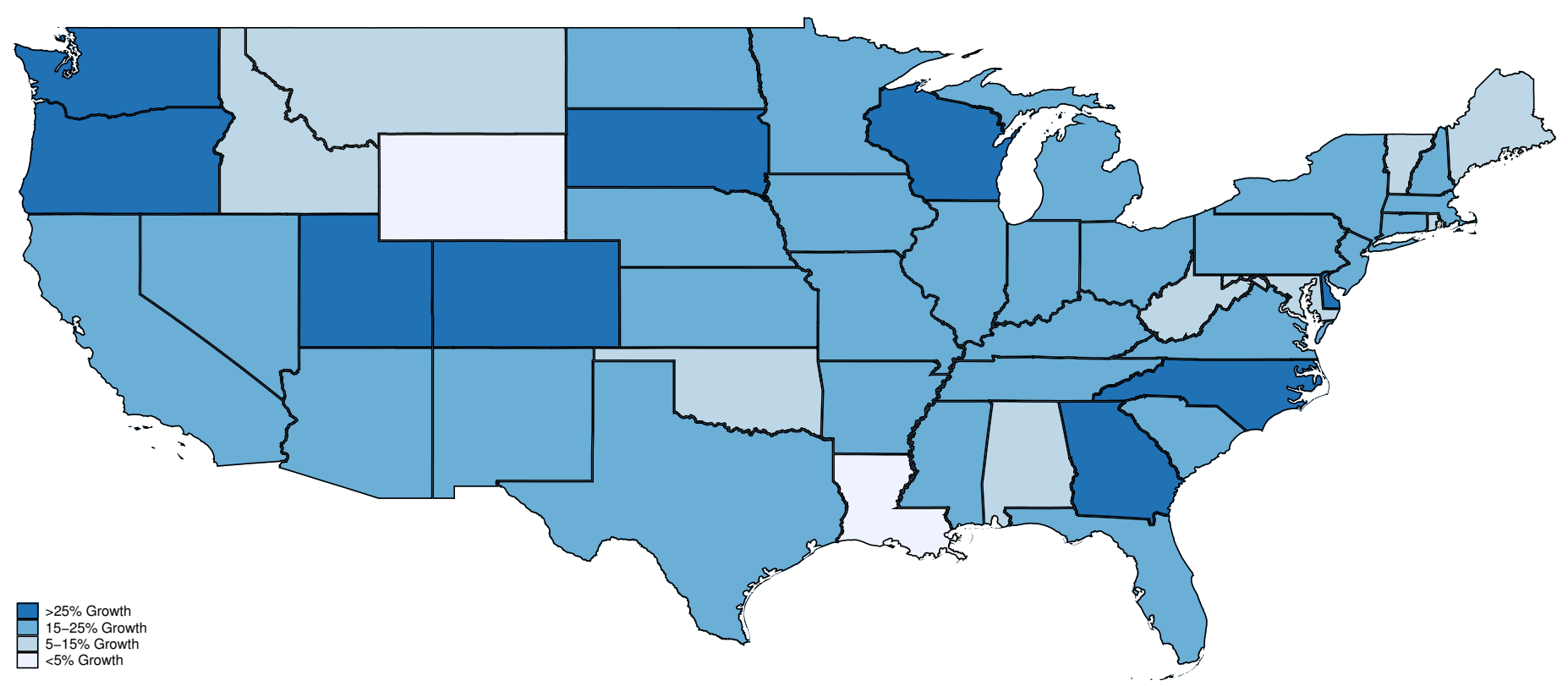

Notes: We use 1990 and 2000 BEA data to construct per capita GDP. This map refers to the percentage change in real terms between 1990 and 2000. 
Figure A.2C: Growth Rate in Real Per Capita GDP by State: 2000-2010

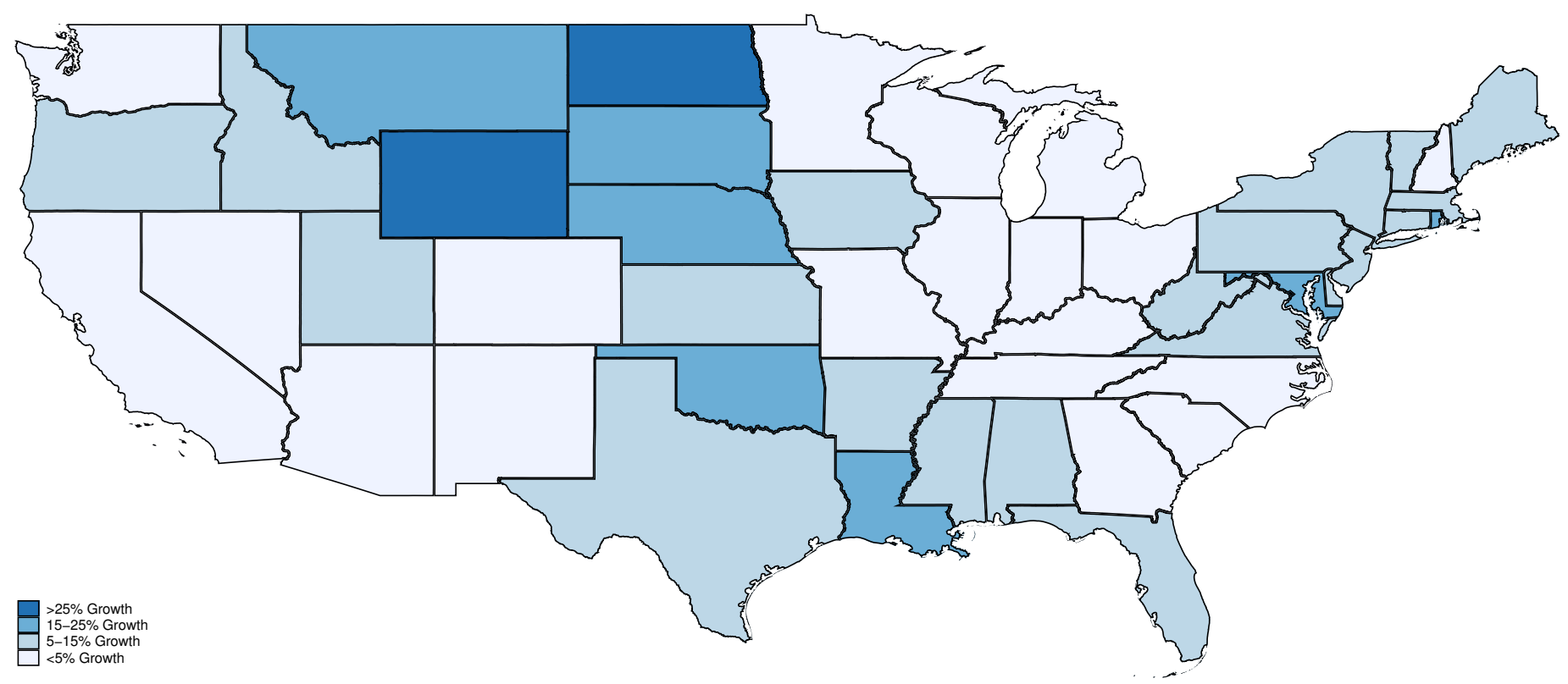

Notes: We use 2000 and 2010 BEA data to construct per capita GDP. This map refers to the percentage change in real terms between 2000 and 2010.

Figure A.3: IV Elasticity Estimate: Dropping One State at a Time

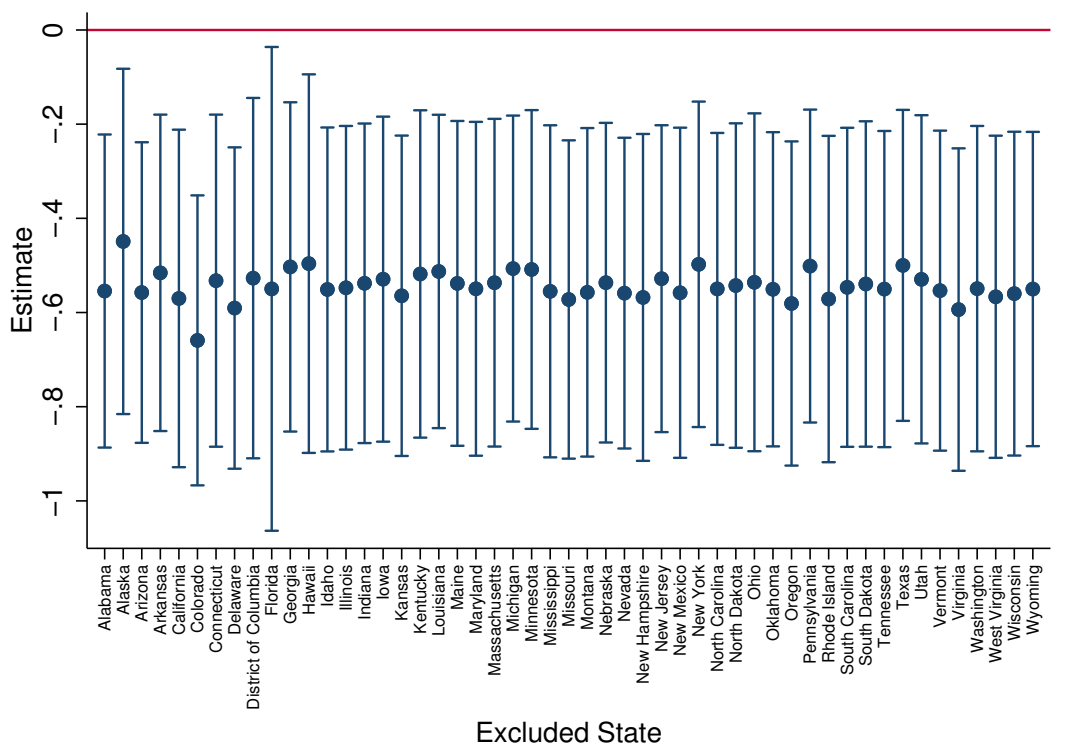

Notes: We replicate the Table 2 , Panel A, first column estimate $(=-0.545)$ but dropping one state at a time to test whether the result is driven by a specific outlier. We plot the estimate and $95 \%$ confidence intervals. See Table 2 notes for more information on estimation. 
Table A.1: Summary Statistics

\begin{tabular}{|c|c|c|c|c|}
\hline \multicolumn{5}{|c|}{$1990,2000,2010(\mathrm{~N}=153)$} \\
\hline & Mean & Standard Dev & Min & Max \\
\hline Fraction of Population $60+$ & 0.240 & 0.029 & 0.095 & 0.313 \\
\hline Percent Change in Fraction of Population $60+$ & 4.258 & 7.901 & -9.089 & 47.073 \\
\hline Predicted Percent Change in Fraction of Population $60+$ & 4.445 & 8.338 & -14.103 & 59.196 \\
\hline Percent Change in GDP per Capita & 8.723 & 9.380 & -34.507 & 45.932 \\
\hline Percent Change in GDP per Worker & 9.051 & 8.003 & -31.608 & 45.216 \\
\hline Percent Change in GDP per Compensation Dollar & 2.090 & 3.631 & -25.977 & 17.660 \\
\hline Percent Change in Employment-to-Population Ratio & -0.314 & 4.225 & -10.022 & 9.262 \\
\hline \multicolumn{5}{|l|}{$1990(\mathrm{~N}=51)$} \\
\hline & Mean & Standard Dev & Min & Max \\
\hline Fraction of Population $60+$ & 0.236 & 0.030 & 0.095 & 0.313 \\
\hline Percent Change in Fraction of Population $60+$ & 2.141 & 4.959 & -6.802 & 25.911 \\
\hline Predicted Percent Change in Fraction of Population $60+$ & 2.307 & 5.078 & -9.113 & 54.631 \\
\hline Percent Change in GDP per Capita & 9.907 & 10.933 & -16.343 & 35.152 \\
\hline Percent Change in GDP per Worker & 4.683 & 9.075 & -18.801 & 27.137 \\
\hline Percent Change in GDP per Compensation Dollar & 3.354 & 3.187 & -10.264 & 12.604 \\
\hline Percent Change in Employment-to-Population Ratio & 4.887 & 1.961 & -1.709 & 9.262 \\
\hline \multicolumn{5}{|c|}{$2000(\mathrm{~N}=51)$} \\
\hline & Mean & Standard Dev & Min & Max \\
\hline Fraction of Population $60+$ & 0.228 & 0.028 & 0.123 & 0.297 \\
\hline Percent Change in Fraction of Population $60+$ & -3.066 & 3.122 & -9.089 & 28.764 \\
\hline Predicted Percent Change in Fraction of Population $60+$ & -2.836 & 4.321 & -14.103 & 39.822 \\
\hline Percent Change in GDP per Capita & 13.934 & 5.651 & -34.507 & 26.181 \\
\hline Percent Change in GDP per Worker & 14.408 & 5.462 & -31.608 & 28.871 \\
\hline Percent Change in GDP per Compensation Dollar & 0.674 & 4.131 & -25.977 & 17.660 \\
\hline Percent Change in Employment-to-Population Ratio & -0.406 & 1.919 & -6.392 & 3.117 \\
\hline \multicolumn{5}{|l|}{$2010(\mathrm{~N}=51)$} \\
\hline & Mean & Standard Dev & Min & Max \\
\hline Fraction of Population $60+$ & 0.255 & 0.024 & 0.181 & 0.308 \\
\hline Percent Change in Fraction of Population $60+$ & 12.324 & 4.678 & 0.219 & 47.073 \\
\hline Predicted Percent Change in Fraction of Population $60+$ & 12.487 & 5.749 & -1.898 & 59.196 \\
\hline Percent Change in GDP per Capita & 3.233 & 7.752 & -18.784 & 45.932 \\
\hline Percent Change in GDP per Worker & 7.676 & 6.315 & -9.738 & 45.216 \\
\hline Percent Change in GDP per Compensation Dollar & 2.370 & 3.068 & -7.499 & 17.042 \\
\hline Percent Change in Employment-to-Population Ratio & -4.208 & 2.259 & -10.022 & 1.806 \\
\hline
\end{tabular}

Notes: Unit of observation is state-year. There are 51 observations per year and 153 total. All percent changes are defined in real terms and refer to ten year changes: $\frac{X_{t}-X_{t-10}}{X_{t-10}}$. "GDP per Compensation Dollar" refers to GDP divided by total compensation to employees (wages and in-kind benefits). The "Predicted Percent Change in Fraction of Population 60+" variable is generated using the $t-10$ age structure and national survival ratios. See equation (2) for details. Population denominators ("per Capita") refer to the age 20+ population. 
Table A.2: Ordinary Least Squares Estimates

\begin{tabular}{ccccc}
\hline Dependent Variable: & \multicolumn{4}{c}{$\Delta \ln (\mathrm{GDP} / \mathrm{N})$} \\
\hline \multirow{3}{*}{$\ln \left(\frac{A}{N}\right)$} & $\underline{1980-2010}$ & $\underline{1980-1990}$ & $\underline{1990-2000}$ & $\underline{2000-2010}$ \\
& $-0.826^{* * *}$ & $-0.853^{* * *}$ & $-1.344^{* * *}$ & $-0.608^{* * *}$ \\
Num. Obs. & $(0.140)$ & $(0.220)$ & $(0.332)$ & $(0.208)$ \\
\hline
\end{tabular}

Notes: Significance Levels: $* 10 \%, * * 5 \%, * * * 1 \%$. Standard errors in parentheses adjusted for clustering at state level. Each observation is weighted by period $t$ population. $\Delta y \equiv y_{s, t+10}-y_{s t}$. Other variables included: year dummies; the log of the fraction of workers in the applicable initial period (i.e., period $t$ ) working in each of the following industries: agriculture, mining, construction, manufacturing, transportation, communications / utilities, wholesale trade, retail trade, finance / insurance / real estate, business and repair services, personal services, recreation services, professional services, and public administration. The industry composition variables are interacted with the time dummies to allow the effects of initial industry composition to vary by year. 
Table A.3: Results by Decade (10 year lagged instrument)

\begin{tabular}{|c|c|c|c|c|}
\hline Panel A: & \multicolumn{4}{|c|}{ Reduced Form Estimates } \\
\hline \multirow[t]{2}{*}{ Dependent Variable: } & \multicolumn{4}{|c|}{$\Delta \ln (\mathrm{GDP} / \mathrm{N})$} \\
\hline & $\underline{1980-2010}$ & $1980-1990$ & $1990-2000$ & $\underline{2000-2010}$ \\
\hline$\Delta \ln \left(\frac{\hat{A}}{\hat{N}}\right)$ & $\begin{array}{c}-0.390 * * * \\
(0.134)\end{array}$ & $\begin{array}{c}-0.563^{* *} \\
(0.215)\end{array}$ & $\begin{array}{l}-0.375 \\
(0.429)\end{array}$ & $\begin{array}{c}-0.306^{* *} \\
(0.172)\end{array}$ \\
\hline Num. Obs. & 153 & 51 & 51 & 51 \\
\hline Panel B: & \multicolumn{4}{|c|}{ First Stage Estimates } \\
\hline \multirow[t]{2}{*}{ Dependent Variable: } & \multicolumn{4}{|c|}{$\Delta \ln (\mathrm{A} / \mathrm{N})$} \\
\hline & $\underline{1980-2010}$ & $\underline{1980-1990}$ & $\underline{1990-2000}$ & $\underline{2000-2010}$ \\
\hline$\Delta \ln \left(\frac{\hat{A}}{\hat{N}}\right)$ & $\begin{array}{c}0.716^{* * *} \\
(0.054)\end{array}$ & $\begin{array}{c}0.627^{* * *} \\
(0.119)\end{array}$ & $\begin{array}{c}0.504^{* * *} \\
(0.161)\end{array}$ & $\begin{array}{c}0.865^{* * *} \\
(0.071)\end{array}$ \\
\hline Num. Obs. & 153 & 51 & 51 & 51 \\
\hline Panel C: & \multicolumn{4}{|c|}{ Instrumental Variable Estimates } \\
\hline \multirow[t]{2}{*}{ Dependent Variable: } & \multicolumn{4}{|c|}{$\Delta \ln (\mathrm{GDP} / \mathrm{N})$} \\
\hline & $\underline{1980-2010}$ & 1980-1990 & $\underline{1990-2000}$ & $\underline{2000-2010}$ \\
\hline$\Delta \ln \left(\frac{A}{N}\right)$ & $\begin{array}{c}-0.545^{* * *} \\
(0.173)\end{array}$ & $\begin{array}{c}-0.898^{* *} \\
(0.336)\end{array}$ & $\begin{array}{c}-0.744 \\
(0.655)\end{array}$ & $\begin{array}{c}-0.354^{* *} \\
(0.194)\end{array}$ \\
\hline Num. Obs. & 153 & 51 & 51 & 51 \\
\hline
\end{tabular}

Notes: Significance Levels: ${ }^{*} 10 \%, * * 5 \%, * * * 1 \%$. Standard errors in parentheses adjusted for clustering at state level. Each observation is weighted by period $t$ population. $\Delta y \equiv y_{s, t+10}-y_{s t}$. Other variables included: year dummies; the log of the fraction of workers in the applicable initial period (i.e., period $t$ ) working in each of the following industries: agriculture, mining, construction, manufacturing, transportation, communications / utilities, wholesale trade, retail trade, finance / insurance / real estate, business and repair services, personal services, recreation services, professional services, and public administration. The industry composition variables are interacted with the time dummies to allow the effects of initial industry composition to vary by year. We estimate using 2SLS with the 10 year lagged instrument. 
Table A.4: Effects of Other Age Groups

\begin{tabular}{|c|c|c|c|c|}
\hline Dependent Variable: & \multicolumn{4}{|c|}{$\Delta \ln (\mathrm{GDP} / \mathrm{N})$} \\
\hline$\Delta \ln ($ Ages $30-39 / N)$ & $\begin{array}{l}-0.112 \\
(0.192)\end{array}$ & & & \\
\hline$\Delta \ln ($ Ages $40-49 / N)$ & $\begin{array}{l}-0.279 \\
(0.226)\end{array}$ & $\begin{array}{l}-0.261 \\
(0.218)\end{array}$ & & \\
\hline$\Delta \ln ($ Ages $50-59 / \mathrm{N})$ & $\begin{array}{l}-0.104 \\
(0.228)\end{array}$ & $\begin{array}{l}-0.051 \\
(0.200)\end{array}$ & $\begin{array}{l}-0.063 \\
(0.198)\end{array}$ & \\
\hline$\Delta \ln ($ Ages $60+/ N)$ & $\begin{array}{c}-0.594^{* * *} \\
(0.191)\end{array}$ & $\begin{array}{c}-0.550^{* * *} \\
(0.153)\end{array}$ & $\begin{array}{c}-0.527^{* * *} \\
(0.164)\end{array}$ & $\begin{array}{c}-0.545^{* * *} \\
(0.173)\end{array}$ \\
\hline Num. Obs & 153 & 153 & 153 & 153 \\
\hline Dependent Variable: & \multicolumn{4}{|c|}{$\Delta \ln (\mathrm{GDP} / \mathrm{N})$} \\
\hline$\Delta$ Ages $30-39 / \mathrm{N}$ & $\begin{array}{l}-0.539 \\
(0.939)\end{array}$ & & & \\
\hline$\Delta$ Ages $40-49 / \mathrm{N}$ & $\begin{array}{l}-1.576 \\
(1.197)\end{array}$ & $\begin{array}{l}-1.45 \\
(1.177)\end{array}$ & & \\
\hline$\Delta$ Ages $50-59 / \mathrm{N}$ & $\begin{array}{l}-0.848 \\
(1.615)\end{array}$ & $\begin{array}{l}-0.462 \\
(1.399)\end{array}$ & $\begin{array}{l}-0.543 \\
(1.391)\end{array}$ & \\
\hline$\Delta$ Ages $60+/ \mathrm{N}$ & $\begin{array}{c}-2.252^{* *} \\
(0.894)\end{array}$ & $\begin{array}{c}-2.019^{* * * *} \\
(0.748)\end{array}$ & $\begin{array}{c}-1.901^{* *} \\
(0.795)\end{array}$ & $\begin{array}{c}-2.030^{* *} \\
(0.828)\end{array}$ \\
\hline Num. Obs. & 153 & 153 & 153 & 153 \\
\hline
\end{tabular}

Notes: Significance Levels: $* 10 \%, * * 5 \%, * * * 1 \%$. Standard errors in parentheses adjusted for clustering at state level. Each observation is weighted by period $t$ population. $\Delta y \equiv y_{s, t+10}-y_{s t}$. Other variables included: year dummies; the $\log$ of the fraction of workers in the applicable initial period (i.e., period $t$ ) working in each of the following industries: agriculture, mining, construction, manufacturing, transportation, communications / utilities, wholesale trade, retail trade, finance / insurance / real estate, business and repair services, personal services, recreation services, professional services, and public administration. The industry composition variables are interacted with the time dummies to allow the effects of initial industry composition to vary by year. We estimate using 2SLS with the 10 year lagged instruments. In the bottom half of the table, age share levels (not logs) are used. The instruments are also expressed in levels. 
Table A.5: Controlling for Initial Per Capita GDP

\begin{tabular}{ccc}
\hline Dependent Variable: & \multicolumn{2}{c}{$\Delta \ln (G D P / N)$} \\
\hline & $(1)$ & $(2)$ \\
$\Delta \ln \left(\frac{A}{N}\right)$ & $-0.603^{* * *}$ & $-0.778^{* * *}$ \\
Instruments for $\Delta \ln (G D P / N)_{t}$ & $10+$ years & $20+$ years \\
Num. Obs. & 153 & 153 \\
\hline
\end{tabular}

Notes: Significance Levels: ${ }^{*} 10 \%,{ }^{*} 5 \%,{ }^{* * *} 1 \%$. Standard errors in parentheses adjusted for clustering at state level. Each observation is weighted by period $t$ population. $\Delta y \equiv y_{s, t+10}-y_{s t}$. Other variables included: year dummies; the log of the fraction of workers in the applicable initial period (i.e., period $t$ ) working in each of the following industries: agriculture, mining, construction, manufacturing, transportation, communications / utilities, wholesale trade, retail trade, finance / insurance / real estate, business and repair services, personal services, recreation services, professional services, and public administration. The industry composition variables are interacted with the time dummies to allow the effects of initial industry composition to vary by year. We estimate using IV-GMM with the 10 year lagged instrument. We also control for $\Delta \ln (G D P / N)_{t}$ and consider this variable endogenous. In Column (1), we include lagged levels of the log of per capita GDP for years $t-10$ and earlier as instruments. In Column (2), we use lagged levels of the log of per capita GDP for years $t-20$ and earlier as instruments.

Table A.6: Including Leads: 1980-2000

\begin{tabular}{ccc}
\hline Dependent Variable: & \multicolumn{2}{c}{$\Delta \ln (G D P / N)_{t+10}$} \\
\hline & $(1)$ & $(2)$ \\
$\Delta \ln \left(\frac{A}{N}\right)_{t+10}$ & $-0.833^{* *}$ & $-1.012^{* * *}$ \\
$\Delta \ln \left(\frac{A}{N}\right)_{t+20}$ & $(0.361)$ & $(0.329)$ \\
& & 0.131 \\
Num. Obs. & 102 & $(0.266)$ \\
\end{tabular}

Notes: Significance Levels: $* 10 \%, * * 5 \%, * * * 1 \%$. Standard errors in parentheses adjusted for clustering at state level. Each observation is weighted by period $t$ population. $\Delta y_{t+10} \equiv y_{s, t+10}-y_{s t}$. Other variables included: year dummies; the log of the fraction of workers in the applicable initial period (i.e., period $t$ ) working in each of the following industries: agriculture, mining, construction, manufacturing, transportation, communications / utilities, wholesale trade, retail trade, finance / insurance / real estate, business and repair services, personal services, recreation services, professional services, and public administration. The industry composition variables are interacted with the time dummies to allow the effects of initial industry composition to vary by year. We estimate using 2SLS with the 10 year lagged instrument. In Column (1), we estimate our main specification using only 1980-2000 data. In Column (2), we add the change in aging for the next 10 years. The instruments are the predicted aging variables for years $t+10$ (as before) and $t+20$ (new). 
Table A.7: Instrumental Variable Poisson Estimates: Effect of Aging on GDP Growth

\begin{tabular}{ccccc}
\hline Dependent Variable: & \multicolumn{4}{c}{ GDP / N } \\
\hline & $\underline{1980-2010}$ & $\underline{1980-1990}$ & $\underline{1990-2000}$ & $\underline{2000-2010}$ \\
$\Delta \ln \left(\frac{A}{N}\right)$ & $-0.509^{* * *}$ & $-0.924^{* * *}$ & $-0.962^{* *}$ & $-0.337^{* *}$ \\
Num. Obs. & $(0.129)$ & $(0.283)$ & $(0.453)$ & $(0.136)$ \\
& 153 & 51 & 51 & 51
\end{tabular}

Notes: Significance Levels: $* 10 \%, * * 5 \%, * * * 1 \%$. Standard errors in parentheses adjusted for clustering at state level. Each observation is weighted by period $t$ population. $\Delta y \equiv y_{s, t+10}-y_{s t}$. The outcome is period $t+1$ per capita GDP. Period $t \log$ of GDP per capita is included as an offset (the coefficient is constrained to equal 1). Other variables included: year dummies; the log of the fraction of workers in the applicable initial period (i.e., period $t$ ) working in each of the following industries: agriculture, mining, construction, manufacturing, transportation, communications / utilities, wholesale trade, retail trade, finance / insurance / real estate, business and repair services, personal services, recreation services, professional services, and public administration. The industry composition variables are interacted with the time dummies to allow the effects of initial industry composition to vary by year. We estimate using IV-Poisson with the 10 year lagged instrument.

Table A.8: Instrumental Variable Estimates: Weighted vs Unweighted Results

\begin{tabular}{ccccc}
\hline Dependent Variable: & \multicolumn{5}{c}{$\Delta \ln (\mathrm{GDP} / \mathrm{N})$} \\
\hline & \multicolumn{5}{c}{ Weighted by Population } \\
$\Delta \ln \left(\frac{A}{N}\right)$ & $-0.545^{* * *}$ & $\frac{1980-1990}{-0.898^{* *}}$ & $\frac{1990-2000}{-0.744}$ & $\frac{2000-2010}{-0.354^{* *}}$ \\
& $(0.173)$ & $(0.336)$ & $(0.655)$ & $(0.194)$ \\
Num. Obs. & 153 & 51 & 51 & 51 \\
\hline & $\underline{5}$ & Unweighted \\
$\Delta \ln \left(\frac{A}{N}\right)$ & $-0.478^{* * *}$ & $\frac{1980-1990}{1980-2010}$ & $\underline{1990-2000}$ & $\underline{2000-2010}$ \\
& $(0.161)$ & $(0.319)$ & $-0.996^{* * *}$ & $-0.258^{* *}$ \\
Num. Obs. & 153 & 51 & 51 & 51
\end{tabular}

Notes: Significance Levels: $* 10 \%, * * 5 \%, * * * 1 \%$. Standard errors in parentheses adjusted for clustering at state level. $\Delta y \equiv y_{s, t+10}-y_{s t}$. Other variables included: year dummies; the log of the fraction of workers in the applicable initial period (i.e., period $t$ ) working in each of the following industries: agriculture, mining, construction, manufacturing, transportation, communications / utilities, wholesale trade, retail trade, finance / insurance / real estate, business and repair services, personal services, recreation services, professional services, and public administration. The industry composition variables are interacted with the time dummies to allow the effects of initial industry composition to vary by year. We estimate using 2SLS with the 10 year lagged instrument. 
Table A.9: IV Estimates with Region-Year Interactions: Effect of Aging on GDP Growth

\begin{tabular}{ccccc}
\hline Dependent Variable: & \multicolumn{4}{c}{$\Delta \ln (\mathrm{GDP} / \mathrm{N})$} \\
\hline & $\underline{1980-2010}$ & $\frac{1980-1990}{-0.690}$ & $\frac{1990-2000}{-0.895}$ & $\underline{2000-2010}$ \\
$\Delta \ln \left(\frac{A}{N}\right)$ & $-0.585^{* *}$ & $0.447^{* *}$ \\
& 153 & 51 & 51 & 51
\end{tabular}

Notes: Significance Levels: ${ }^{*} 10 \%, * * 5 \%, * * * 1 \%$. Standard errors in parentheses adjusted for clustering at state level. Each observation is weighted by period $t$ population. $\Delta y \equiv y_{s, t+10}-y_{s t}$. Other variables included: year dummies interacted with Census Region indicators; the log of the fraction of workers in the applicable initial period (i.e., period $t$ ) working in each of the following industries: agriculture, mining, construction, manufacturing, transportation, communications / utilities, wholesale trade, retail trade, finance / insurance / real estate, business and repair services, personal services, recreation services, professional services, and public administration. The industry composition variables are interacted with the time dummies to allow the effects of initial industry composition to vary by year. We estimate using 2SLS with the 10 year lagged instrument.

Table A.10: Using Previous Year's State of Residence: 2000-2010

\begin{tabular}{ccccc}
\hline & OLS & Reduced Form & First Stage & IV \\
\hline$\Delta \ln \left(\frac{A}{N}\right)$ & $-0.634^{* * *}$ & $-0.348^{* *}$ & $0.878^{* * *}$ & $-0.396^{* *}$ \\
& $(0.204)$ & $(0.174)$ & $(0.070)$ & $(0.192)$ \\
Num. Obs. & 51 & 51 & 51 & 51 \\
\hline
\end{tabular}

Notes: Significance Levels: ${ }^{*} 10 \%, * * 5 \%, * * * 1 \%$. Standard errors in parentheses adjusted for clustering at state level. Each observation is weighted by period $t$ population. $\Delta y \equiv y_{s, t+10}-y_{s t}$. Other variables included: year dummies; the log of the fraction of workers in the applicable initial period (i.e., period $t$ ) working in each of the following industries: agriculture, mining, construction, manufacturing, transportation, communications / utilities, wholesale trade, retail trade, finance / insurance / real estate, business and repair services, personal services, recreation services, professional services, and public administration. The industry composition variables are interacted with the time dummies to allow the effects of initial industry composition to vary by year. For this table, $\Delta \ln \left(\frac{A}{N}\right)$ (and the corresponding instrument) are generated using each individual's prior year state of residence. This information is first available in the 2000 Census. $\Delta \ln \left(\frac{A}{N}\right)$ refers to the predicted value in the Reduced Form and First Stage columns. We estimate using 2SLS with the 10 year lagged instrument. 


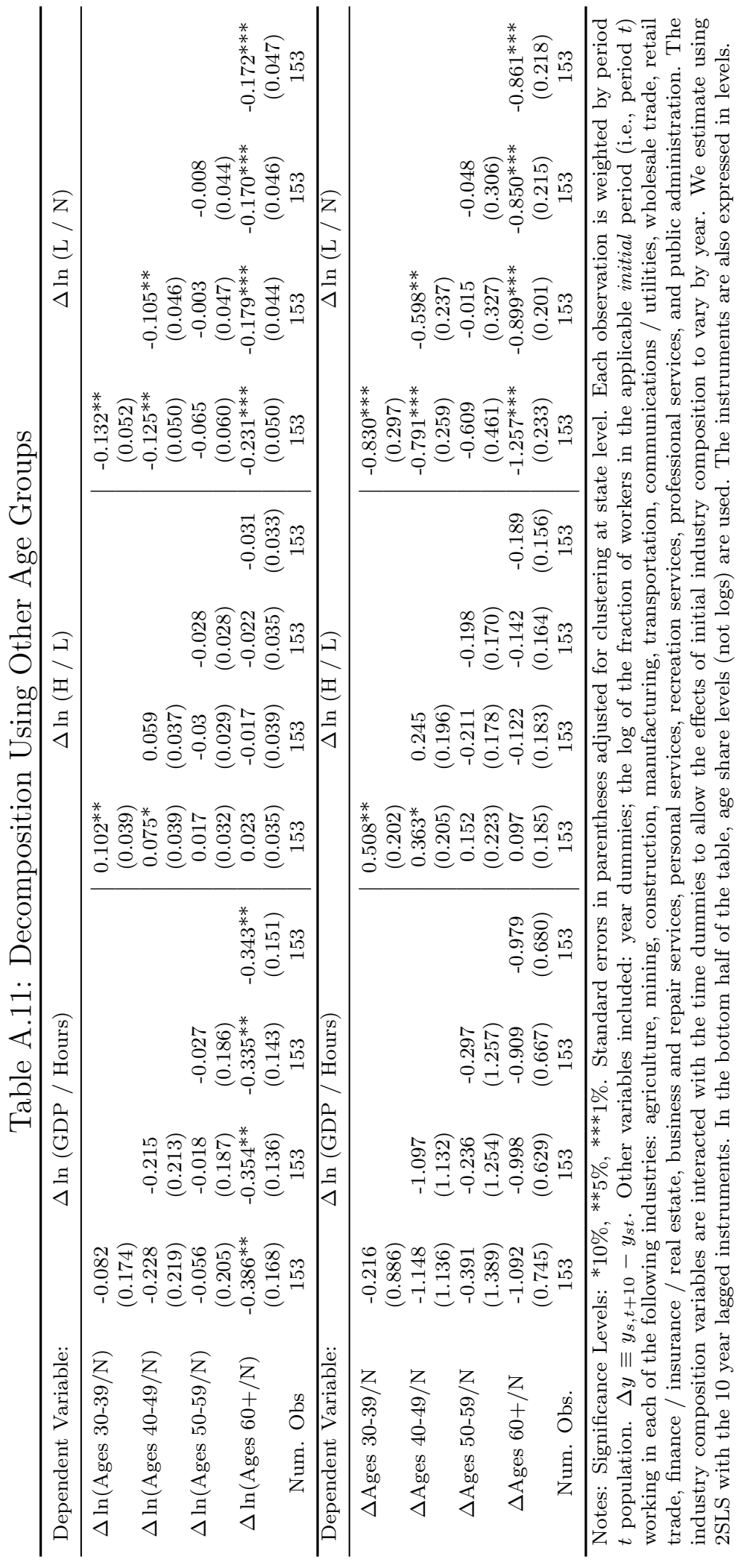


Table A.12: Decomposing Main Effect - Alternative Instrument Lag Lengths

\begin{tabular}{|c|c|c|c|c|}
\hline Instrument Length: & (1) & $\begin{array}{l}(2) \\
20 \text { Year Lag }\end{array}$ & (3) & $(4)$ \\
\hline $\begin{array}{l}\text { Dependent Variable: } \\
\qquad \Delta \ln \left(\frac{A}{N}\right)\end{array}$ & $\begin{array}{c}\Delta \ln (\mathrm{GDP} / \mathrm{N}) \\
-0.503^{* * *} \\
(0.184)\end{array}$ & $\begin{array}{c}\Delta \ln (\text { GDP } / \text { Hours }) \\
-0.285^{*} \\
(0.147)\end{array}$ & $\begin{array}{c}\Delta \ln (\mathrm{H} / \mathrm{L}) \\
-0.027 \\
(0.037)\end{array}$ & $\begin{array}{c}\Delta \ln (\mathrm{L} / \mathrm{N}) \\
-0.191^{* * *} \\
(0.053)\end{array}$ \\
\hline Instrument Length: & & 30 Year Lag & & \\
\hline $\begin{array}{l}\text { Dependent Variable: } \\
\qquad \Delta \ln \left(\frac{A}{N}\right)\end{array}$ & $\begin{array}{c}\Delta \ln (\text { GDP / N }) \\
-0.450^{* *} \\
(0.214)\end{array}$ & $\begin{array}{c}\Delta \ln (\text { GDP } / \text { Hours }) \\
-0.266 \\
(0.193)\end{array}$ & $\begin{array}{c}\Delta \ln (\mathrm{H} / \mathrm{L}) \\
-0.033 \\
(0.035)\end{array}$ & $\begin{array}{c}\Delta \ln (\mathrm{L} / \mathrm{N}) \\
-0.151^{* * *} \\
(0.047)\end{array}$ \\
\hline Instrument Length: & & 40 Year Lag & & \\
\hline $\begin{array}{l}\text { Dependent Variable: } \\
\qquad \Delta \ln \left(\frac{A}{N}\right)\end{array}$ & $\begin{array}{c}\Delta \ln (\mathrm{GDP} / \mathrm{N}) \\
-0.543 \\
(0.325)\end{array}$ & $\begin{array}{c}\Delta \ln (\text { GDP / Hours }) \\
-0.279 \\
(0.311)\end{array}$ & $\begin{array}{c}\Delta \ln (\mathrm{H} / \mathrm{L}) \\
-0.023 \\
(0.057)\end{array}$ & $\begin{array}{c}\Delta \ln (\mathrm{L} / \mathrm{N}) \\
-0.241^{* * *} \\
(0.078)\end{array}$ \\
\hline
\end{tabular}

Notation: $\mathrm{L}=$ number of workers; Hours = total number of hours worked

Notes: Significance Levels: ${ }^{*} 10 \%,{ }^{*} 5 \%,{ }^{* * *} 1 \%$. Num. Obs. $=153$ in all regressions. Standard errors in parentheses adjusted for clustering at state level. Each observation is weighted by period $t$ population. $\Delta y \equiv y_{s, t+10}-y_{s t}$. The coefficients presented in Columns (2), (3), and (4) mechanically sum to the main effect presented in Column (1). Other variables included: year dummies; the log of the fraction of workers in the applicable initial period (i.e., period $t$ ) working in each of the following industries: agriculture, mining, construction, manufacturing, transportation, communications / utilities, wholesale trade, retail trade, finance / insurance / real estate, business and repair services, personal services, recreation services, professional services, and public administration. The industry composition variables are interacted with the time dummies to allow the effects of initial industry composition to vary by year. We estimate using 2SLS. 
Table A.13: Effects on Capital per Worker

\begin{tabular}{cccc}
\hline Dependent Variable: & \multicolumn{3}{c}{$\Delta \ln (\mathrm{K} / \mathrm{L})$} \\
\hline$\Delta \ln \left(\frac{A}{N}\right)$ & $\frac{1980-2000}{0.106}$ & $\frac{1980-1990}{0.228}$ & $\frac{1990-2000}{-0.061}$ \\
& $(0.291)$ & $(0.340)$ & $(0.575)$ \\
Num. Obs. & 102 & 51 & 51 \\
\hline
\end{tabular}

Notes: Significance Levels: $* 10 \%, * * 5 \%, * * * 1 \%$. Standard errors in parentheses adjusted for clustering at state level. Each observation is weighted by period $t$ population. $\Delta y \equiv y_{s, t+10}-y_{s t}$. Other variables included: year dummies; the log of the fraction of workers in the applicable initial period (i.e., period $t$ ) working in each of the following industries: agriculture, mining, construction, manufacturing, transportation, communications / utilities, wholesale trade, retail trade, finance / insurance / real estate, business and repair services, personal services, recreation services, professional services, and public administration. The industry composition variables are interacted with the time dummies to allow the effects of initial industry composition to vary by year. We estimate using 2SLS with the 10 year lagged instrument. 


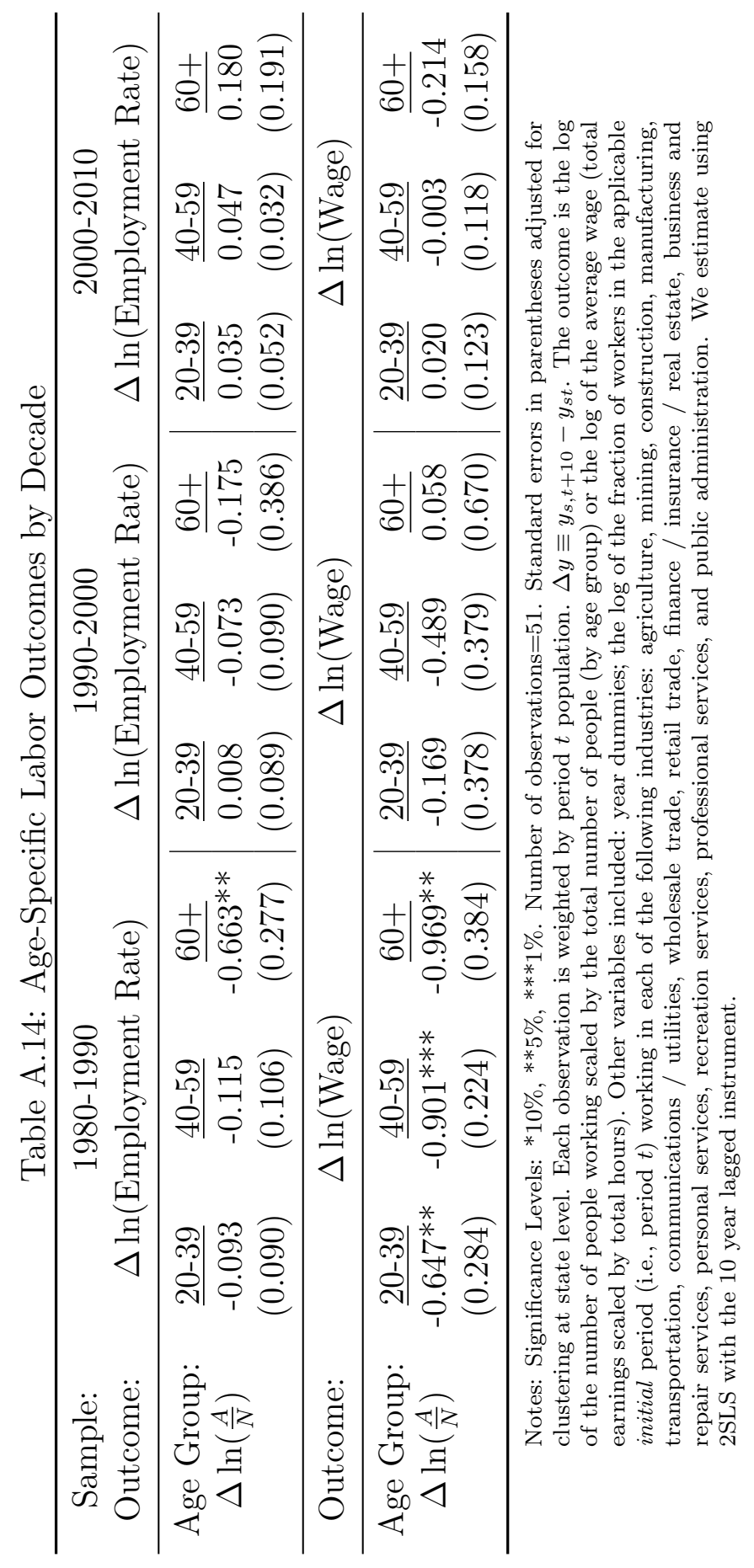

